Full Length Article

\title{
The time-temperature-maturity relationship: A chemical kinetic model of kerogen evolution based on a developed molecule-maturity index
}

\author{
Xiaohe Wang ${ }^{\mathrm{a}, \mathrm{b}}$, Ya-Pu Zhao ${ }^{\mathrm{a}, \mathrm{b}, *}$ \\ ${ }^{a}$ State Key Laboratory of Nonlinear Mechanics, Institute of Mechanics, Chinese Academy of Sciences, Beijing 100190, China \\ ${ }^{\mathrm{b}}$ School of Engineering Science, University of Chinese Academy of Sciences, Beijing 100049, China
}

\section{A R T I C L E I N F O}

\section{Keywords:}

Kerogen thermal evolution

Kerogen maturity index

Vitrinite reflectance

Chemical kinetic model

Activation energy

\begin{abstract}
A B S T R A C T
Kerogen maturity is an important indicator for evaluating source rocks. We propose a kerogen maturity index (molecule-maturity index, MMI) based on the changes in the molecular structure of organic matter during thermal evolution. The MMI has a positive correlation with vitrinite reflectance. Molecular dynamics simulations indicate that the weight loss is with a positive linear correlation with the MMI, demonstrating the ability of the index to reflect the hydrocarbon generation of organic matter. In addition, a new conversion is introduced by the MMI to analyze the kinetics of kerogen thermal evolution. The activation energy is expressed as a continuous function of the MMI linking by the new conversion. The activation energy was calculated at the isoconversional points of previous conversion, which was not defined as a continuous function before. A linear relationship between the activation energy of kerogen is observed, and a new chemical kinetic model of kerogen thermal maturity is established based on the MMI (kinetic model of the maturity evolution, MEKM). The MEKM equation has a simple form and is convenient for engineering applications. Our findings provide insights into the kinetics of kerogen thermal maturation and guide the choice of temperature and time for artificial maturity.
\end{abstract}

\section{Introduction}

Kerogen is the most important form of organic carbon on the planet. Kerogen gradually matures and generates oil/gas after being exposed for a long geological period as chemical evolution of the molecular structure occurs. During this time, the reservoir environment changes $[1,2]$. In addition, kerogen is an extremely complex polymer, consisting of an amorphous porous carbon skeleton [3-5]. The micro/nanopores serve as the primary storage and circulation channels for shale gas [6]. Changes in the pore structure during kerogen evolution are important for understanding the accumulation and migration of shale oil/gas $[7,8]$. During the pyrolysis of kerogen, solids decompose into gas to form micropores. Micropores develop into microcracks under the action of geostress and pore pressure. The microcracks will cause the asymptotic failure of kerogen [9]. In addition, the chemical transformation caused by the kerogen evolution causes a change from a plastic to a brittle rupture mechanism, affecting the hydraulic fracturing of kerogen [3]. Kerogen-rich rock closes rapidly during hydraulic fracturing because kerogen-rich shale exhibits high tensile strength. The reason is that kerogen exhibits strain softening under tension [10]. Therefore, the hydraulic fracturing process of kerogen-rich shale requires large amount of fracturing fluid [11]. The micro-cracks and changes in the mechanical properties of kerogen caused by its evolution affect the hydraulic fracturing process of the rock formation $[12,13]$. The degree of the metamorphism of organic matter (OM) is referred to as maturity, which is a reliable indicator of source rocks. In-situ ripening of kerogen can be achieved through in situ conversion process (ICP), ElectrofracTM and other method to achieve efficient exploitation of oil and gas resources. Technical methods of clean gasification of organic energy have been investigated in depth [14-16]. Therefore, it is important to study the evolution of maturity to understand the generation of shale gas and provide guidance for hydraulic fracturing.

As one of the most important evaluation indices, the kerogen-based evaluation index primarily depends on the organic geochemistry, organic petrology and mineralogy, and chemical kinetics of a site [17]. Optical indices, such as the vitrinite reflectance (VR), microsome reflectance, bitumen reflectance, and gravel reflectance, have been used in organic petrology to characterize the maturity [18-21]; the VR is one of the most reliable and widely used index [22,23]. The vitrinite is widespread in various sedimentary rocks, and is rich in content. The VR changes systematically with the increase of burial temperature [23]. The VR curve is corrected by the algae fluorescence parameters (wavelength of the maximum intensity $\left(\lambda_{\max }\right)$, spectral maxima, emission intensities, etc.) $[24,25]$. The change in the VR is used as a measure of

\footnotetext{
* Corresponding author at: State Key Laboratory of Nonlinear Mechanics, Institute of Mechanics, Chinese Academy of Sciences, Beijing 100190, China.

E-mail address: yzhao@imech.ac.cn (Y.-P. Zhao).
} 


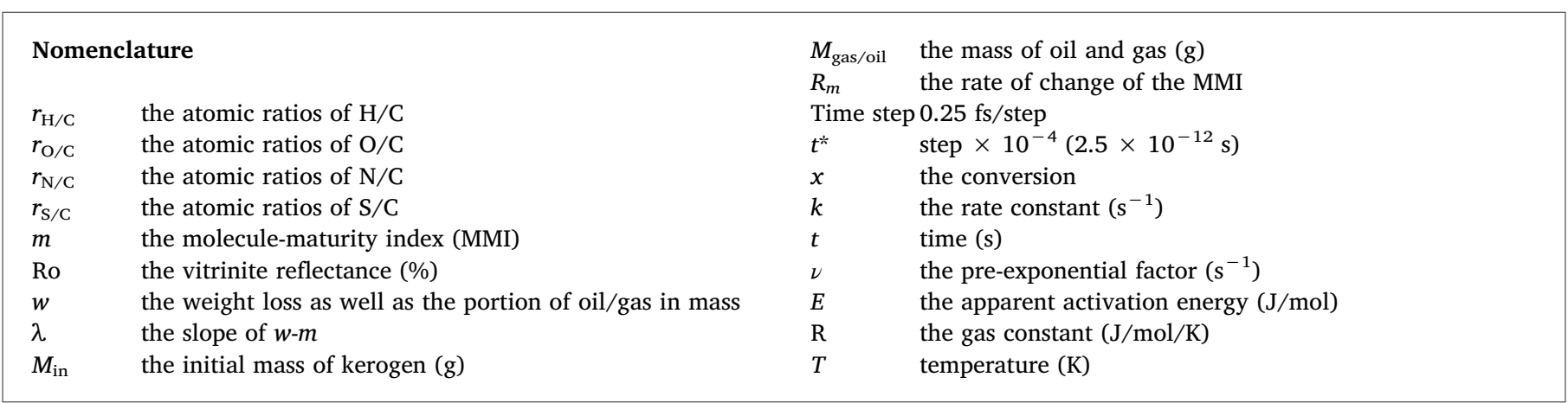

coal conversion in the gasification experiment of coal samples [26]. Zhang et al. used the VR as a benchmark to evaluate the maturity and established the relationship between the parameters of the Raman spectrum (the position of $\mathrm{D}$ band $\left(\mathrm{P}_{\mathrm{D}}\right)$, full width at half maximum of $\mathrm{G}$ band (FWHMG)) and the VR [27]. Another standard detection method is the use of organic geochemistry. $T_{\max }$ at which maximum hydrocarbon generation occurs is another commonly used maturity index, because it increases with increasing maturity. $T_{\max }$ is the maximum S2 peak temperature obtained by Rock-Eval (RE) pyrolysis [28]. Hai et al. analyzed $T_{\max }$ and detected the gas products by combining thermogravimetric analysis (TGA), derivative thermogravimetry (DTG), differential scanning calorimetry (DSC), online gas analyzer and offline gas chromatography (GC) analyzer [29]. However, the VR can only be used in kerogen where huminite/vitrinite phytoclasts are present. The method is not suitable for pre-Silurian shales or marine shale (such as sapropelic sediments) lacking huminite/vitrinite particles [30,31]. The VR suppression is observed in the hydrogen-rich samples and in lacustrine shales under over-pressure. Therefore, the VR is abnormal in the Dongying sample which includes type I and part type II kerogen [32]. The use of $T_{\max }$ is limited in overmature kerogen because S2 peak of overmature kerogen is weak, so $T_{\max }$ is inaccurate [33]. The mineral matrix in the kerogen will cause an abnormally high $T_{\max }$, whereas the soluble organic matter will cause a low $T_{\max }$ [34]. The hydrogen/ carbon $(\mathrm{H} / \mathrm{C})$ atomic ratio, oxygen/carbon $(\mathrm{O} / \mathrm{C})$ atomic ratio, and aromatic/aliphatic ratios were also used to study the maturity. The corrected organic carbon mass content (COC) was also used as a maturity index [35]. Elemental analysis (EA) is typically performed to determine the maturity by defining the evolution path of the kerogen chemical structure with increasing burial depth [36]. The VR value of kerogen is correlated with the $\mathrm{H} / \mathrm{C}$ and $\mathrm{O} / \mathrm{C}$ atomic ratios of kerogen, and the relationship is obtained by experimental fitting $[37,38]$. The type I and type II $\mathrm{H} / \mathrm{C}$ atomic ratios of pyrolyzed kerogen are excellent indicators of the thermal maturity of kerogen because the ratios are related to the degree of thermal conversion of OM [39]. Sinces different types of kerogen have different $\mathrm{H} / \mathrm{C}$ ratios (Type I > Type II > Type III), the atomic ratio is used to describe the maturity based on known kerogen types. The initial and current values of the $\mathrm{H} / \mathrm{C}$ ratios of the kerogen samples are required to determine the kerogen conversion. Type II kerogen follows the trend of the $\mathrm{H} / \mathrm{C}$ and $\mathrm{O} / \mathrm{C}$ atomic ratios in the thermal maturity process [40]. The OM thermal maturity is a continuous process of side-chain detachment and condensation of OM. It is convenient to report the continuous change in the molecular structure of kerogen during its thermal maturity process using simulations. The molecular composition to characterize the maturity is the basis for the thermal evolution of the macromolecular structure and is commonly determined in addition to the $T_{\max }$ and VR. As the activation energy is related to molecular structure, functional relationship between the maturity index we proposed and the activation energy can be easily established comparing with the maturity index using the VR or $T_{\max }$. Therefore, it is of great significance to define a physical maturity index and to investigate its evolution based on the analysis of kerogen molecular elements.
Chemical kinetic models of kerogen pyrolysis can be used to predict the maturity evolution and the hydrocarbon generation of kerogen. The models include the first-order reaction model, independent reaction model, multi-stage first-order reaction model, $n$-order reaction model, parallel first-order reaction model, pseudo-reaction model, and the Friedman model [28,41-43]. TGA and DSC have been performed to analyze the pyrolysis characteristics and kinetic parameters of kerogen [44-47]. The reactivity of biomass in different atmospheres was investigated using TGA and DSC techniques. An $n$-order reaction equation was used to study the kinetic decomposition process of cellulose [48]. The first-order kinetic model has been considered sufficient to characterize the thermal evolution of the Green River oil shale [49]. The parallel first-order reaction model was used to evaluate the accuracy of the TGA and RE methods, and the latter proved to be more accurate [50]. The catalytic effect of water on the pyrolysis has been investigated using the consecutive first-order reaction model [51]. A multi-stage parallel reaction model was used, and the thermal stability of oil shale during pyrolysis was determined by changing the heating rate [52]. Currently, kinetic models that include the weight loss, heat endothermic/exothermic rate, and hydrocarbon generation rate are used to characterize the reaction rate [53]. The activation energy is always calculated using kinetic models which is obtained by hydrocarbon generation/weight loss, whose calculation is not associated with kerogen components. Moreover, in previous models of changes in the activation energy during conversion, the activation energy was calculated at the isoconversional points of the conversion [54]. However, the activation energy is related to the molecular structure. In the index we proposed in this study, the changes in the activation energy resulting from changed in the kerogen structure are obtained, and a continuous equation between the activation energy and maturity is established through the conversion introduced by maturity. We can establish a kinetic equation based on the thermal evolution of kerogen molecular structure.

In this study, a maturity index of kerogen based on the evolution of the elemental content is established (molecule-maturity index (MMI). We use experiments to investigate the temperature-dependent elemental composition changes of OM to obtain the relationship between the MMI and VR. The relationship between the MMI and the weight loss is obtained by simulations and experiments. A kinetic model of the maturity index is proposed under isothermal conditions, and the evolution of the activation energy is established based on the change in the macromolecular structure. The kinetic equation is highly concise and convenient for engineering application, which is used in choosing the temperature and time for artificial maturity of kerogen in future. Our findings provide insights into the thermal evolution laws of kerogen and facilitate the prediction of oil and gas production for artificial maturity. 


\section{Methods}

\subsection{Construction of the kerogen molecule using experiments and simulations}

The burial depth of kerogen is about $3000 \mathrm{~m}$ from Ordos Basin. And the sample is obtained by GBT 19144-2010 (insoluble organic kerogen in sedimentary rocks) method. Soluble organic matter and minerals are removed. The atomic ratios of $\mathrm{C}, \mathrm{H}, \mathrm{O}, \mathrm{N}$, and $\mathrm{S}$ in kerogen were obtained by EA (Thermo fisher Flash 2000) and X-ray photoelectron spectroscopy (XPS, ESCALab220i-XL). A computation multi-peak resolution method was performed by XPSPEAK41 to analyze the XPS spectra to obtain the chemical states and quantitative relationships of the elements in the kerogen. Under X-ray excitation, the energy-level splitting is generated in $2 \mathrm{p}$ layer electrons of $\mathrm{S}$ due to spin-orbit coupling $\left(2 \mathrm{p}_{1 / 2}\right.$ and $\left.2 \mathrm{p}_{3 / 2}\right)$. For example, $\mathrm{N}$ and $\mathrm{S}$ exist in the form of amino, thioether, etc. The functional groups of the kerogen molecule were determined by Fourier-transform infrared (FT-IR) spectroscopy, and the relative content was qualitatively characterized by the peak intensity. The aromaticity, aliphaticity, branching degree of the alkyl chain and the average aliphatic chain lengths were obtained by crosspolarization/magic angle spinning (CP/MAS) ${ }^{13} \mathrm{C}$ solid nuclear magnetic resonance $\left({ }^{13} \mathrm{C}\right.$ NMR) spectrum technology; subsequently, the kerogen carbon skeleton was established. The methods and instruments used in the experiments are listed in Table 1.

The process of determining the average molecular structure of the kerogen is shown in Fig. 1: first, the aromatic rings and the condensed aromatic rings are the basic units, which are connected by the alkyl side chain. The contents of aromatic $\mathrm{C}$ and aliphatic $\mathrm{C}$ are determined by the XPS spectra and the ${ }^{13} \mathrm{C}$ NMR spectrum, and the ratio of methylene $\mathrm{C}$, protonic aromatic $\mathrm{C}$, etc. are obtained from the ${ }^{13} \mathrm{C}$ NMR spectrum. Then, the $\mathrm{O}, \mathrm{N}$, and $\mathrm{S}$ atoms are distributed in the carbon skeleton based on the heteroatom chemical state information obtained from XPS. A two-dimensional (2D) macromolecule is constructed. Subsequently, the ${ }^{13} \mathrm{C}$ NMR spectrum of $2 \mathrm{D}$ molecule is predicted by the MestReNova software suite to verify the accuracy of the molecule. The experimental and calculation results are compared. The 2D molecular structure is continuously adjusted until the spectrum is consistent with that of the experiment. Finally, a reliable average molecular structure of kerogen is obtained. The 2D kerogen macromolecule is optimized by molecular mechanics and an annealing algorithm, to obtain a three-dimensional minimum energy configuration. The structure energy minimization process was implemented in the Materials Studio/Forcite module. The specific process is described in Ref. [55]. The kerogen macromolecule is used to study the pyrolysis of kerogen using reactive force field-molecular dynamics (Reaxff-MD). The reaction mechanism, oil/gas content, residue quality and molecular structure can be obtained to use in the reaction kinetic models.

\subsection{Simulations of kerogen pyrolysis}

Kerogen evolved during a long geological process. Molecular dynamics (MD) simulation of the reaction force field was performed to calculate the process of bond breaking and generation in the chemical reactions (Fig. A1) [56-58]. A heating strategy is generally used to ensure that the kerogen pyrolysis occurs on picosecond time scale.
Thus, the simulation temperature is much higher than the experimental temperature. First, we used pyrolysis-gas chromatography-mass spectrometry (PY-GC-MS) to analyze the kerogen pyrolysis and demonstrate that ReaxFF-MD simulations can be used for kerogen pyrolysis. The pyrolysis products include $\mathrm{CH}_{4}, \mathrm{H}_{2}$, alkanes, alkenes, aromatic cluster structure and fatty acids. The types of pyrolysis products obtained from the simulations are the same as those obtained from the experiment. However, since the experiments are conducted in an open system and the temperature is lower than that of the simulation, more long chains $\left(\mathrm{C}_{6+}\right)$ are obtained in the experiment, and more short chains are obtained in the simulation. The intermediate and final products of kerogen obtained from the Reaxff-MD simulation are also similar to that of GC-MS in the previous study [59]. Second, an accelerated Reaxff-MD simulation is used to compare the proportional relationship between the gas products and residue. The mass fractions of $\mathrm{CH}_{4}, \mathrm{C}_{2}$ and the residue are $0.0039,0.0044$, and 0.81 , respectively in the pyrolysis experiment and $0.0046,0.0053$, and 0.73 , respectively in the simulation. The higher residue fraction in the experiment is attributed to the impurities in the kerogen. The experimental and simulation results are very close. Third, the dehydrogenation reaction, long chain cleavage, and $\mathrm{CO}_{2}$ generation by removing the carboxyl functional groups were obtained from the simulation. The results were consistent with the reaction mechanism obtained in previous experiments, and the simulation results are shown in Fig. A1. Salmon et al. found that the thermal decomposition process of Morwell coal obtained by ReaxFF-MD was in good agreement with that of the experiment, indicating that the method can be applied to complex OM [60]. Finally, the activation energy and pre-exponential factor were obtained using Reaxff-MD to simulate the pyrolysis of $n$-dodecane, and the results were similar to the experimental results. In addition, when the model obtained through macro experiments was mapped to the time length and temperature using ReaxFF-MD, a simple comparison between the kinetic model and the ReaxFF simulation results at different temperatures was used to determine the conversion rate of hydrocarbons; satisfactory results are obtained [61]. Although the simulation temperature and time scale were different from those of the experiments, the simulation results could be compared with the experimental results. In addition, the radical reaction mechanism cannot be obtained experimentally [62]. The temperature is the main factor affecting pyrolysis, and different temperatures have a significant influence on the pyrolysis reaction. Therefore, we used a large temperature range in the simulation. In addition, this work is focused on the evolution of pyrolysis residues at different temperatures. In the simulations we can easily obtain the structure and composition changes of the kerogen residues at different temperatures. Since the simulation temperature range is large, we extend the law of $\mathrm{OM}$ evolution to natural or experimental temperatures. The force field was HCONSB.ff, which has been used in polymer systems, such as coal pyrolysis. The kerogen molecule was placed in a large lattice $\left(70 \times 70 \times 70 \AA^{3}\right)$. A $2 \times 2 \times 1$ supercell of kerogen molecules was generated to ensure appropriate simulation results. The supercell had 6536 atoms, as shown in Fig. 2. The MD simulations were performed using the NVT (Velocity Verlet + Berendsen) ensemble, and periodic boundary conditions (PBC) were used. Since the temperature is the most important factor affecting the reaction rate of kerogen, we investigated the effect of temperature on the evolution of kerogen using constant temperature simulations in the range of $1900-2800 \mathrm{~K}$. The

Table 1

The methods and instruments used to construct the kerogen molecule.

\begin{tabular}{|c|c|c|c|c|}
\hline Experiment & Instrument & Analysis performed & Software & Results \\
\hline XPS & ESCALab220i-XL & Peak splitting & XPSPEAK41 & Chemical states \\
\hline EA & Thermo fisher Flash 2000 & - & - & Element content \\
\hline${ }^{13} \mathrm{C}$ NMR & BRUKER AVANCE III $400 \mathrm{M}$ & Peak splitting & MestReNova & Carbon skeleton information \\
\hline FT-IR & Nicolet 6700 & - & - & Functional groups \\
\hline
\end{tabular}




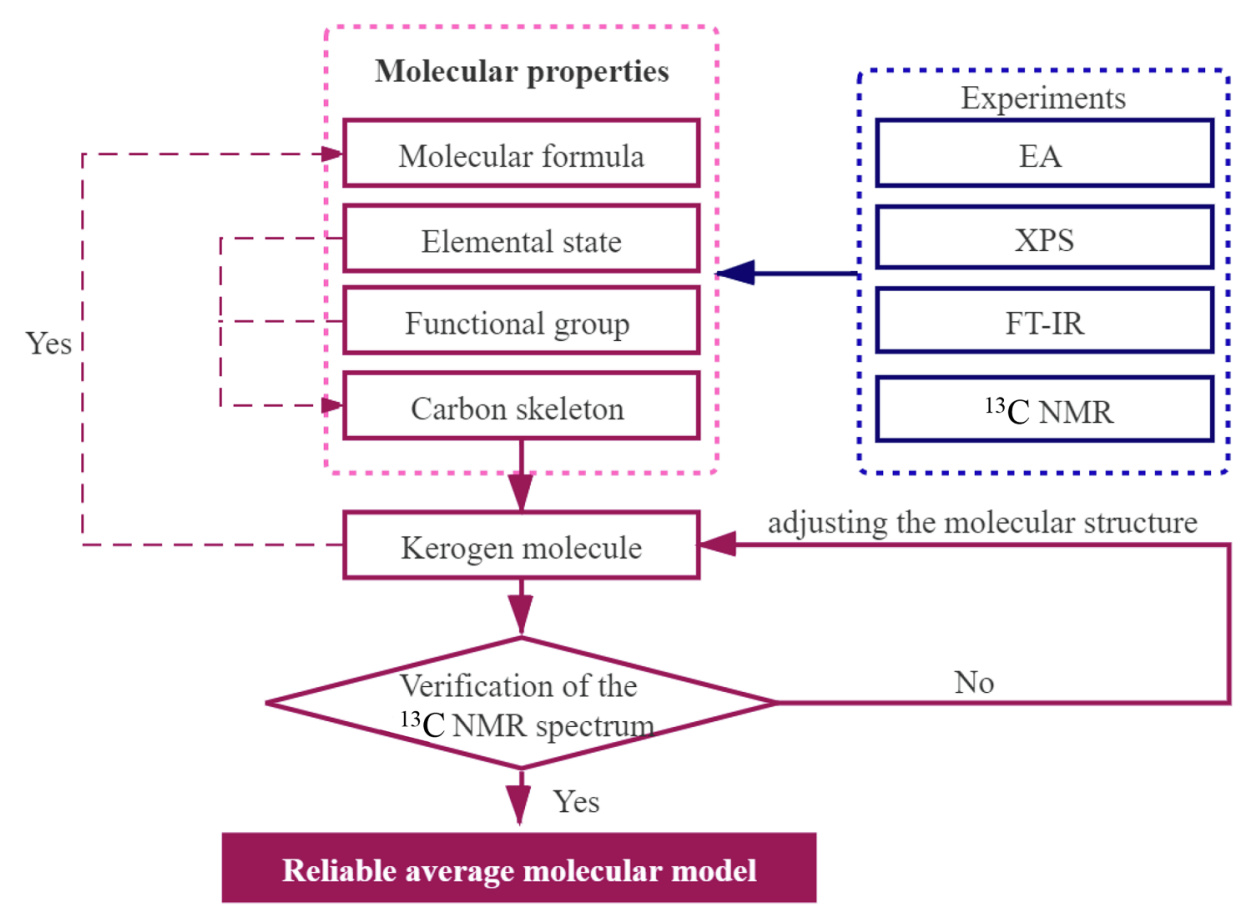

Fig. 1. The flow chart of kerogen molecular structure analysis.

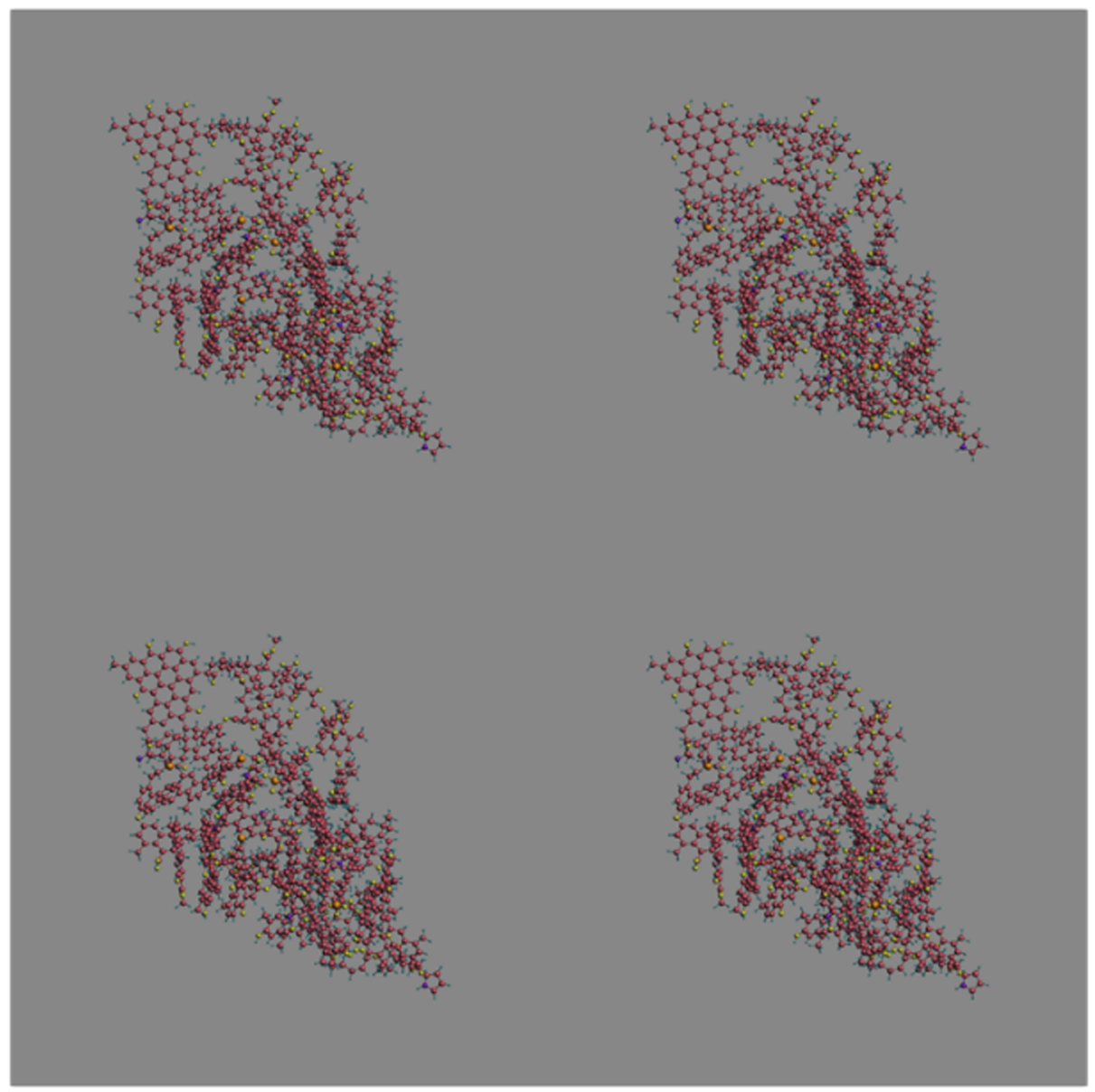

Fig. 2. The macromolecular supercell. 
temperature interval of each simulation was $100 \mathrm{~K}$, and the time step was 400,000 (100 ps).

\section{Results and discussion}

\subsection{The molecule-maturity index}

\subsubsection{Experimental results of kerogen molecular information}

We briefly describe the spectra results obtained by the experiments, because they have been systematically described in our previous paper for the construction of kerogen molecules [55]. The kerogen sample is a type III kerogen based on the van Krevelen diagram; it is at the catagenetic stage. The atomic ratios of $\mathrm{H} / \mathrm{C}$ and $\mathrm{O} / \mathrm{C}$ are about 0.86 and $0.12-0.15$, respectively. By FT-IR spectrum of kerogen, the functional groups contain hydroxyl, aromatic, alkane, ether, aldehyde/ketone, carboxylic, aldehyde, and amidogen. By the overlapping peak resolution of ${ }^{13} \mathrm{C}$ NMR spectrum, the $\mathrm{C}$ skeleton information is obtained. The $\mathrm{C}$ atom contents of methyl, methylene, methine/quaternary, oxy-Methylene, oxy-Methine/oxy-quaternary, ortho-Oxyaromatic protonated, ortho-Oxyaromatic branched, aromatic protonated, bridging ring junction/aromatic branched, oxy-aromatic, and carboxyl/carbonyl are $4.0 \%, 22 \%, 12 \%, 1.5 \%, 2.8 \%, 2.5 \%, 11 \%, 20 \%, 21 \%, 0.5 \%$, and $1.8 \%$, respectively. The elemental states of $\mathrm{C}$ contain aromatic hydrocarbon (37.38\%), aliphatic hydrocarbon (48.64\%), ether/alcohol $(6.31 \%)$, carbonyl/O-C-O (1.80\%), ester/carboxyl (5.87\%)); these of O contain ester/carbonyl (52.72\%), ether/hydroxy (31.47\%), ester/carboxyl (15.81\%)); these of $\mathrm{N}$ contain nitrile $(56.93 \%)$, pyrrole $(32.59 \%)$, amino(10.48\%)); and these of $S$ contain mercaptan/thioether (44.28\%), thiophene (15.26\%), sulfoxide (4.35\%), sulfone (36.11\%)).

The aromaticity degree, aliphaticity degree, branching degree and average aliphatic chain length are 55.9\%, 42.3\%, 28.4\% and 3, respectively. The average molecular formula is about $\mathrm{C}_{100} \mathrm{H}_{86} \mathrm{O}_{13} \mathrm{NS}_{0.8}$. The macromolecular structure of the kerogen was constructed based on the experimental results, and the rationality of the structure has been verified in Ref. [55]. The Reaxff-MD was performed to study the thermal evolution of kerogen by the macromolecule (Fig. 2).

\subsubsection{The definition of the molecule-maturity index}

During the evolution of kerogen for geological or artificial maturity, the $\mathrm{H} / \mathrm{C}$ and $\mathrm{O} / \mathrm{C}$ atomic ratios decrease, and the maturity of kerogen increase along with oil/gas generation. Fig. 3 shows the evolution of the kerogen macromolecules at different temperatures based on the kerogen molecule $\mathrm{C}_{853} \mathrm{H}_{756} \mathrm{~N}_{8} \mathrm{O}_{115} \mathrm{~S}_{6}$, which is type III kerogen from the Ordos basin [55]. Under the combined action of time and temperature, pyrolysis of kerogen occurs, and the evolution of the $\mathrm{H} / \mathrm{C}$ and $\mathrm{O} / \mathrm{C}$ atomic ratios in the residue $\left(\mathrm{C}_{40+}\right.$ molecules $)$ is obtained. The $\mathrm{O} / \mathrm{C}$ and $\mathrm{H} / \mathrm{C}$ atomic ratios in the kerogen decrease as the pyrolysis proceeds, which means the burial depth and maturity increase in the van Krevelen diagram. The result indicates the $\mathrm{O} / \mathrm{C}$ and $\mathrm{H} / \mathrm{C}$ atomic ratios change the pathway of the geological maturity rather than that of the laboratory pyrolysis. However, the temperatures of the simulations are closer to the lab temperatures. This may be due to the fact that no oxygen was injected during the simulations and the pyrolysis products were always in the simulation systems. Compared with the experiment in an open system, in the simulation system, there is material exchange with the outside world. In addition, during the cracking process, gas molecules are continuously generated and the pressure increases at high temperatures. Monthioux et al. [35] found that the experimental results of artificial maturity were qualitatively similar to those of natural systems in a closed and confined system under high temperature. Thus, the simulation pathway is closer to the geological process. With the increase in the temperature, the $\mathrm{O} / \mathrm{C}$ and $\mathrm{H} / \mathrm{C}$ atomic ratios of the residue approach the origin (the black line in Fig. 3), which indicates that the kerogen evolution and maturity are accelerated at high temperatures.

The decline rates of the $\mathrm{H} / \mathrm{C}$ and $\mathrm{O} / \mathrm{C}$ atomic ratios are both positively related to the temperature, as shown in Fig. 4(a) and (b).
Therefore, the $\mathrm{H} / \mathrm{C}$ and $\mathrm{O} / \mathrm{C}$ atomic ratios can be used to predict the maturity. Because the chemical composition of kerogen affects its oil-gas potential and mechanical properties, it is necessary to define a maturity index of the kerogen based on the elemental composition of the molecule. Thus, the atomic ratios of $\mathrm{H} / \mathrm{C}$ and $\mathrm{O} / \mathrm{C}$ are used to characterize the maturity. However, to date, few studies have focused on the quantitative maturity index based on the molecular structure; therefore, we define the index as follows:

$m=\frac{1}{1+r_{\mathrm{H} / \mathrm{C}}+r_{\mathrm{O} / \mathrm{C}}+r_{\mathrm{N} / \mathrm{C}}+r_{\mathrm{S} / \mathrm{C}}}$

to characterize the maturity of kerogen. The $1, r_{\mathrm{H} / \mathrm{C}}, r_{\mathrm{O} / \mathrm{C}}, r_{\mathrm{N} / \mathrm{C}}$ and $r_{\mathrm{S} / \mathrm{C}}$ are the atomic ratios of $\mathrm{C} / \mathrm{C}, \mathrm{H} / \mathrm{C}, \mathrm{O} / \mathrm{C}$, nitrogen/carbon (N/C) and sulfur/carbon (S/C), respectively. As shown in Fig. 4(c) and (d), The N/ $\mathrm{C}$ and $\mathrm{S} / \mathrm{C}$ atomic ratios in the residue decrease over time. However, the $\mathrm{N} / \mathrm{C}$ and S/C atomic ratios exhibit significant fluctuations with increasing temperature and increasing time. In particular, the $\mathrm{S} / \mathrm{C}$ atomic ratio fluctuates greatly between the 150,000th and 390,000th steps (Fig. 4(d)). There exist very few $\mathrm{N}$ and $\mathrm{S}$ atoms in kerogen, and there is an order of magnitude difference between the number of $\mathrm{N}$ and $\mathrm{S}$ atoms and that of the $\mathrm{H}$ and $\mathrm{O}$ atoms. In addition, the van Krevelen diagram shows only the $\mathrm{H} / \mathrm{C}$ and $\mathrm{O} / \mathrm{C}$ atomic ratios; these are used to define the type of kerogen. The content of $\mathrm{H}$ atoms in the kerogen affects the hydrocarbon generation. The content of $\mathrm{O}$ atoms is directly related to the formation of carbon dioxide. When the S/C and N/C atomic ratios are ignored in Eq. (1), the simplified MMI using the atomic ratios is written as follows:

$m=\frac{1}{1+r_{\mathrm{H} / \mathrm{C}}+r_{\mathrm{O} / \mathrm{C}}}$

Since the index is based on the molecular composition of OM, we call it the MMI. The atomic ratios of $\mathrm{H} / \mathrm{C}$ and $\mathrm{O} / \mathrm{C}$ are variables of the MMI. In kerogen pyrolysis, the dehydrogenation reaction, polycondensation reactions and side chain removal reactions occur to generate oil/gas. $\mathrm{CO}_{2}$ is generated by the pyrolysis of oxygen-containing groups. The atomic ratios of $\mathrm{H} / \mathrm{C}$ and $\mathrm{O} / \mathrm{C}$ decrease with the thermal evolution of kerogen. As shown in Fig. A1, an increase in the MMI indicates an increase in the proportion of benzene rings in kerogen, a decrease in the proportion of - $\mathrm{CH} 2$ - groups, and a decrease

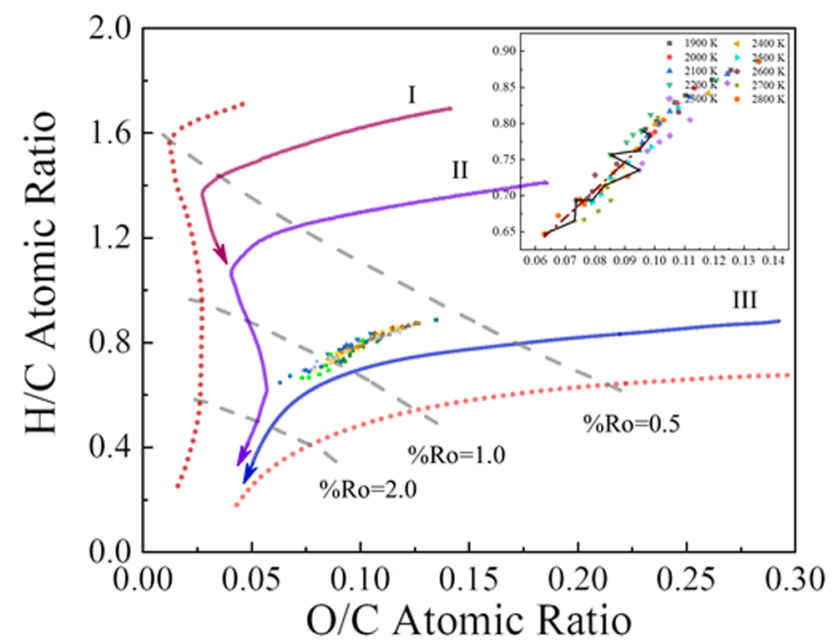

Fig. 3. The evolution of $\mathrm{OM}$ in the van Krevelen diagram at different temperatures. The $\mathrm{H} / \mathrm{C}$ and $\mathrm{O} / \mathrm{C}$ atomic ratios of kerogen are between the two dotted lines. The solid lines show the evolution of type I, II, and III kerogens, and the arrows indicate the direction of increasing burial depth. In the inset in the upper right corner, the dark red polyline is the line connecting the data of the 390,000-step from $1900 \mathrm{~K}$ to $2800 \mathrm{~K}$, and the dark red dotted line is a linear fit of the connection. (For interpretation of the references to colour in this figure legend, the reader is referred to the web version of this article.) 
(a)

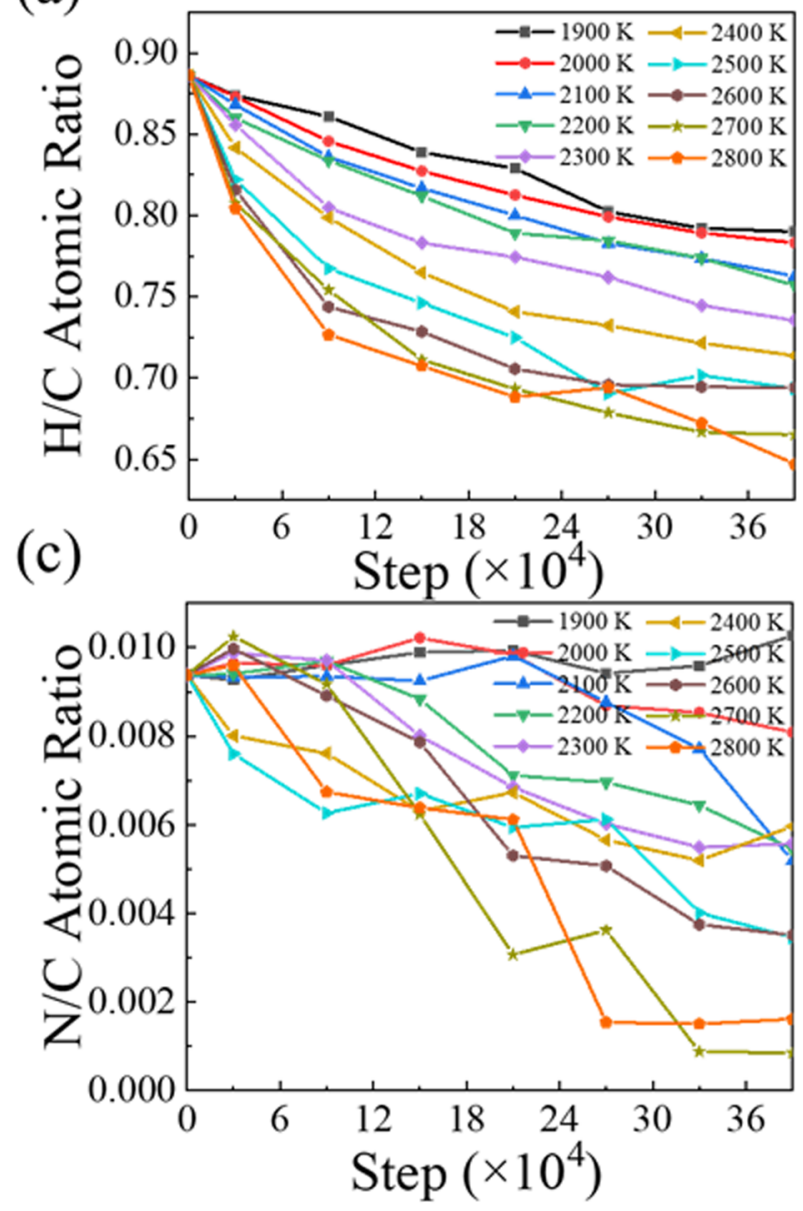

(b)
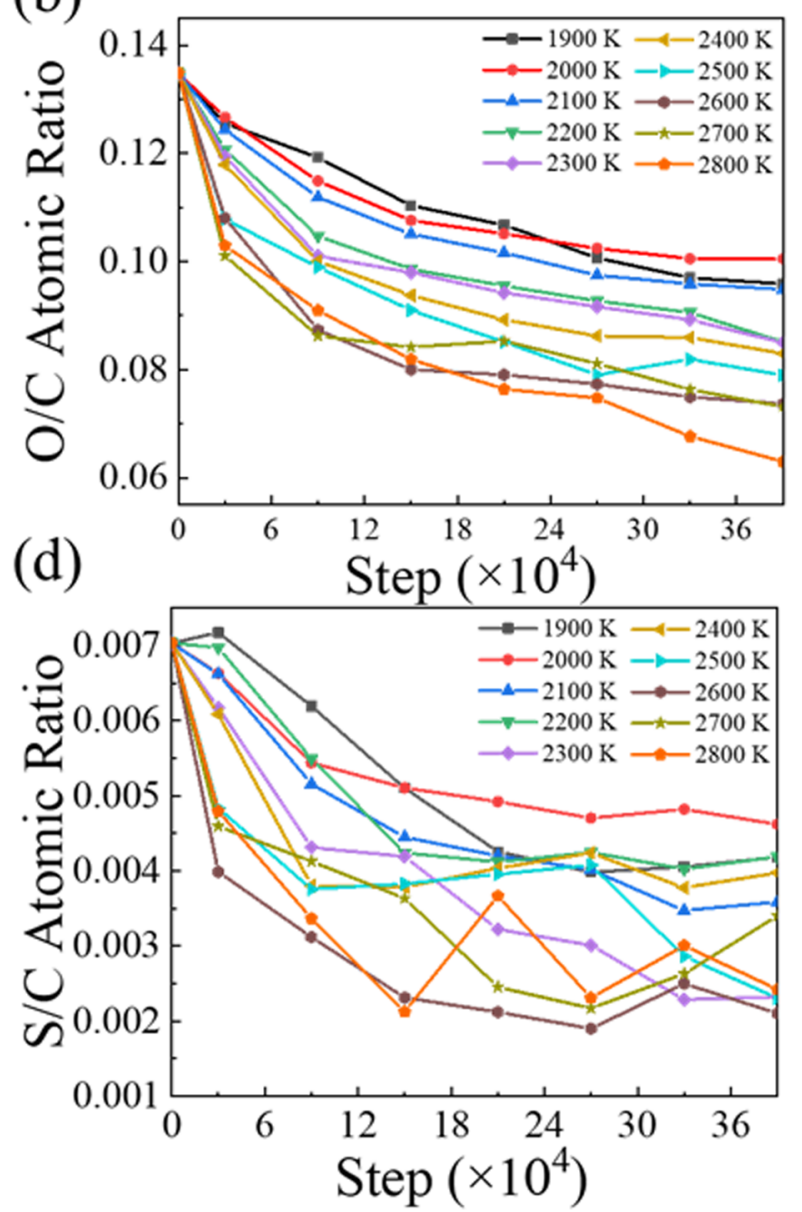

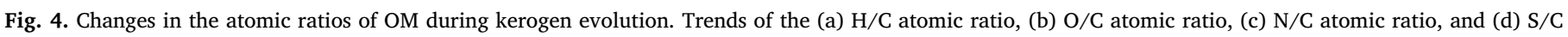
atomic ratio at different temperatures.

in the proportion of oxygen-containing structures.

When $m=1$, the kerogen is completely carbonized $\left(r_{\mathrm{H} / \mathrm{C}}=r_{\mathrm{O} / \mathrm{C}}=0\right)$, which is the limit state of $m$. At present, the evolution of OM maturity is primarily characterized by the VR. Based on the experimental data of the pyrolysis of the kerogen samples and coal [63-66], the values of $m$ in the OM evolution are calculated; they are compared with the corresponding VR, as shown in Fig. 5. The relationship between the MMI and the VR of the residue is positive and approximately linear. The relationship between the $\mathrm{H} / \mathrm{C}$ and $\mathrm{O} / \mathrm{C}$ atomic ratios and the VR for the natural maturity is written as \% Ro $=12 \exp \left(-3.2 r_{\mathrm{H} / \mathrm{C}}\right)-r_{\mathrm{O} / \mathrm{C}}($ Vitrimat2018) [37]. In this study, we do not discuss the use of the MMI to calculate the VR. Our results show that the MMI is positively related to the VR, demonstrating that the proposed MMI is well suited to reflect the evolution of maturity.

Since $m$ is a function of the molecular composition, we investigate the kinetics of the OM evolution from the perspective of the molecular structure as an independent index. The relationship between $m$ and the $\mathrm{H} / \mathrm{C}$ and $\mathrm{O} / \mathrm{C}$ atomic ratios has been established. A 3D van Krevelen diagram was created (Fig. 6). It is observed that $m$ increases with an increase in the buried depth.

\subsubsection{Maturity versus weight loss}

The ratio of weight loss reflects the quantity of kerogen to generate hydrocarbons. Kerogen pyrolysis simulations were performed at different temperatures. The weight loss of the kerogen increases over time under isothermal conditions, as shown in the histogram in Fig. 7 (a). The relationship between the MMI and the weight loss $w$ of kerogen is established to determine the quantity of oil/gas generation. When kerogen reaches a certain maturity, the rates of weight loss and maturity evolution slow down. There is a positive linear correlation between weight loss and the MMI (Fig. 7(b)). The equation describing the relationship between $w$ and $m$ is $w=\lambda\left(m-m_{0}\right)$, where $\lambda=8.43$ is the fitting parameter, $m$ and $m_{0}$ are the current MMI and initial MMI,

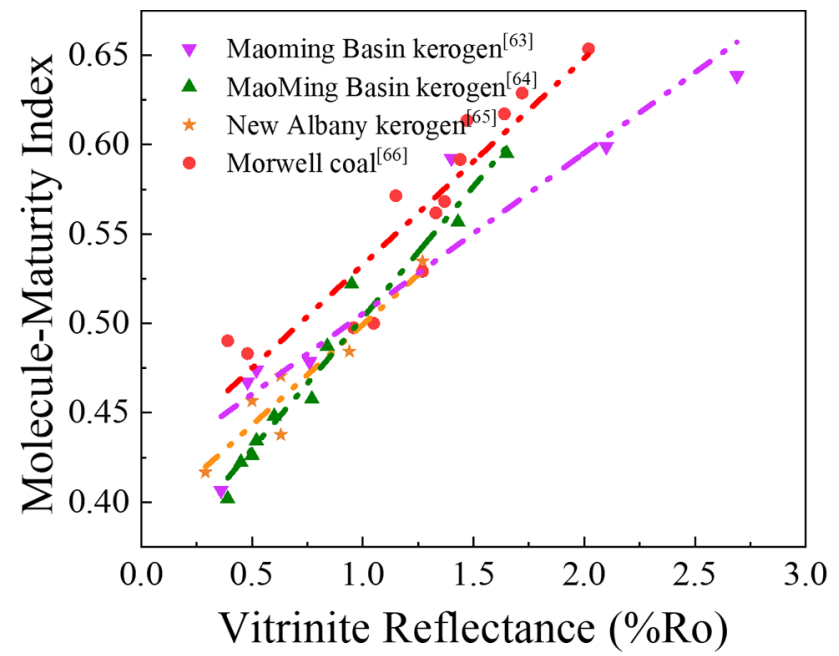

Fig. 5. The correlation between the VR and the MMI. The points are obtained from the experimental data in Ref. [63-66]. 


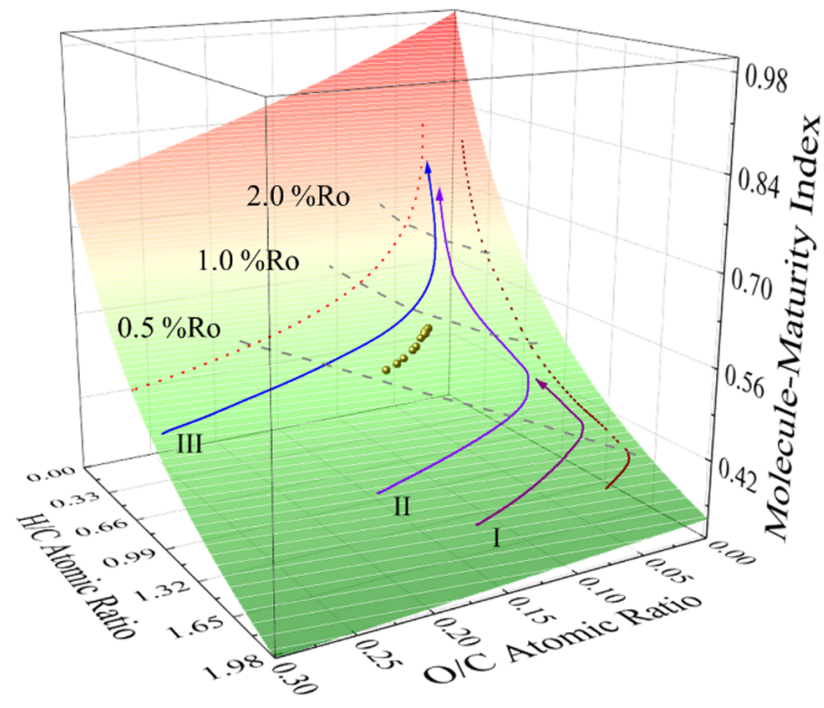

Fig. 6. 3D van Krevelen diagram and the relationship between $m$ and the H/C and $\mathrm{O} / \mathrm{C}$ atomic ratios. The spheres indicate that the value of $m$ increases with changes in the $\mathrm{H} / \mathrm{C}$ and $\mathrm{O} / \mathrm{C}$ atomic ratios in the residue at $1900 \mathrm{~K}$.

respectively. The slope $\lambda$ of the line does not change significantly with changes in the temperature, indicating that the temperature does not affect the relationship between $m$ and $w$. The weight loss of kerogen occurs due to the generation of $\mathrm{H}_{2} \mathrm{O}, \mathrm{CO}_{2}$, small hydrocarbons, and other products. These are the primary components of shale oil/gas. The $w$ represents the weight loss, as well as the portion of oil/gas in mass. Therefore, the weight loss directly reflects the amount of produced oil/ gas $M_{\text {gas/oil }}(\mathrm{g})$ by kerogen pyrolysis $\left(M_{\text {gas/oil }}=w M_{\text {in }}\right)$. The quantity of produced oil/gas can be calculated as follows: $M_{\text {gas } / \text { il }}=w M_{\text {in }}=\lambda\left(m-m_{0}\right) M_{\text {in }}$, where $M_{\text {in }}(\mathrm{g})$ is the initial mass of kerogen. We calculate the MMI value using the data in table 5 of Ref. [66]. The relationship between the MMI and the weight loss is plotted in Fig. B1. It is observed that relationship is also approximately linear, but the slope is smaller than that of the simulations. There may be two reasons: first, the sample used in the simulations is type III kerogen, and the sample of Ref. [66] is coal. At the same temperature, the order of the weight loss is type I kerogen $>$ type II kerogen $>$ type III kerogen $>$ coal. Second, the residue we obtained consists of $\mathrm{C}_{40+}$ molecules, whereas the residue of Ref. [66] consists of $\mathrm{C}_{14+}$ molecules; therefore, the weight loss in our simulations is greater than that of Ref. [66].

In addition, the solid residue of kerogen pyrolysis can be divided

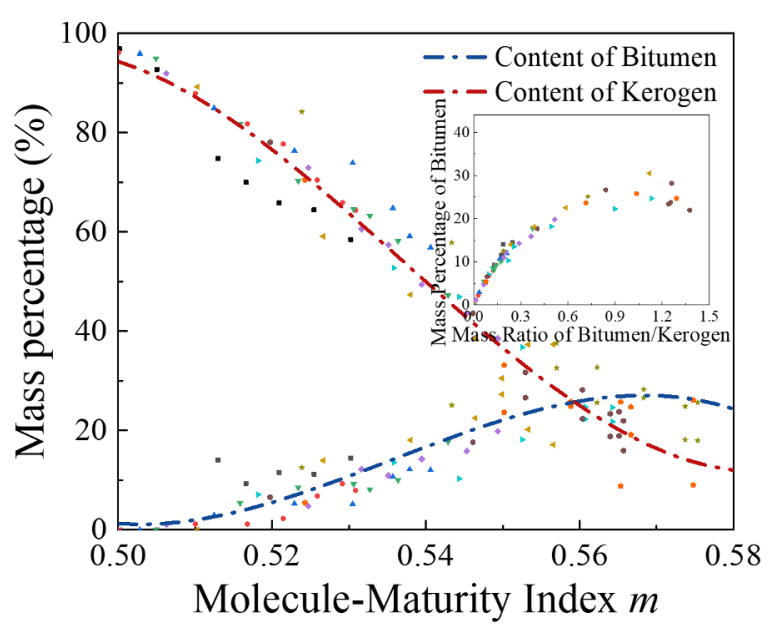

Fig. 8. Comparison of the bitumen and kerogen content in the organic residue for different values of $m$.

into two parts. The soluble part in the organic solvents is called bitumen, and the insoluble part is kerogen. The molecular weight of bitumen should not exceed 1,400 [67]. Therefore, bitumen and kerogen are distinguished by their molecular weight. We consider molecules with more than 100C atoms in the residue as kerogen molecules. The molecules from $\mathrm{C}_{40}$ to $\mathrm{C}_{100}$ are considered to be bitumen in this work, whose molecular weight typically exceeds 500 . The bitumen molecules contain $\mathrm{C}, \mathrm{H}, \mathrm{O}, \mathrm{N}$, and $\mathrm{S}$ atoms. The $\mathrm{C}_{40}$ - molecules are oil and gas molecules, which contains $\mathrm{CH}_{4}, \mathrm{CO}_{2}, \mathrm{H}_{2} \mathrm{~S}, \mathrm{C}_{2}-\mathrm{C}_{5}$, Naphtha, etc. The trends of the bitumen mass and kerogen mass versus $m$ are shown in Fig. 8. As the MMI increases, the rate of kerogen decomposition decreases. The bitumen mass increased in the early stage of kerogen evolution and dropped in the later stage. Bitumen is produced by kerogen pyrolysis and is pyrolyzed into smaller molecules. The two reactions proceed simultaneously. When the rate of bitumen decomposition is higher than the rate of bitumen production, a decline in the bitumen mass occurs. As shown in the inset in Fig. 8, when the ratio of the bitumen content to the kerogen content in the residue is near 1 , the bitumen mass begins to decrease.

\subsection{Chemical kinetic model of kerogen based on MMI}

\subsubsection{Comparison and selection of kinetic evolution equations}

The kerogen conversion rate is closely related to the temperature. The $\mathrm{H} / \mathrm{C}$ and $\mathrm{O} / \mathrm{C}$ ratios of the kerogen residue at different (a)

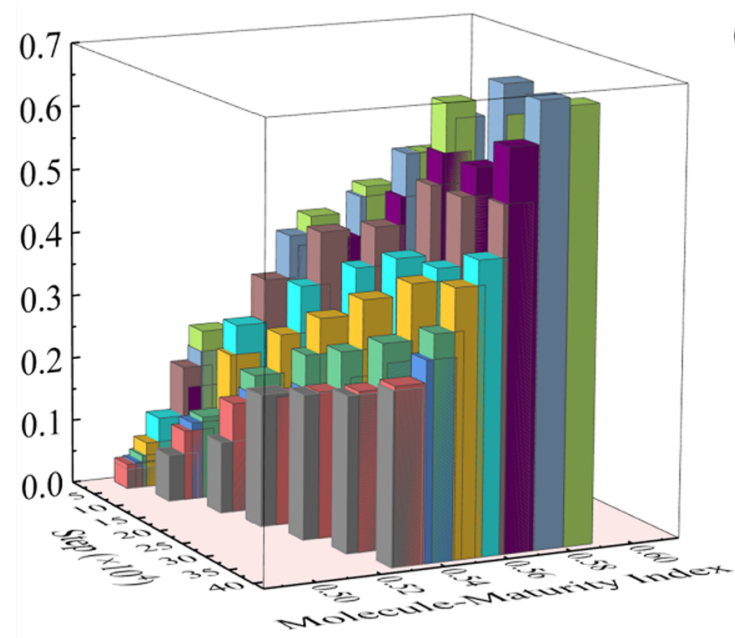

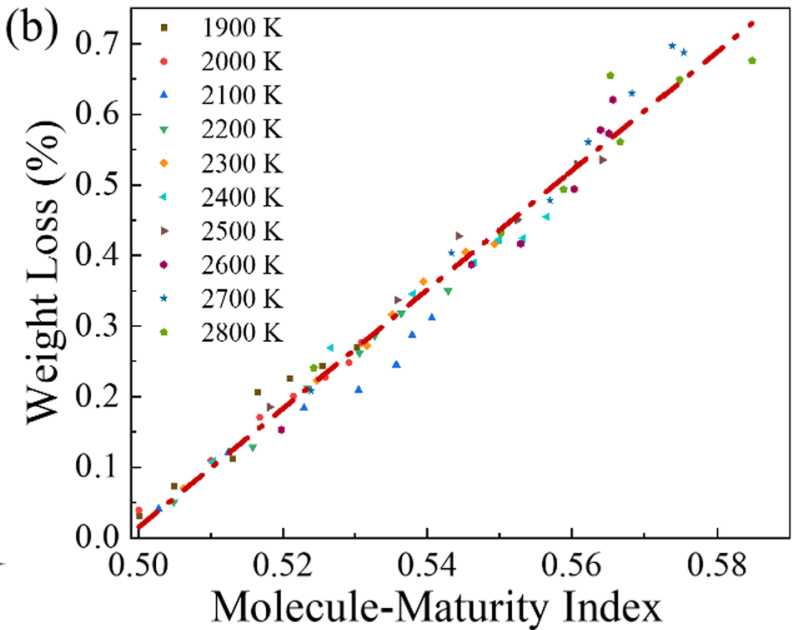

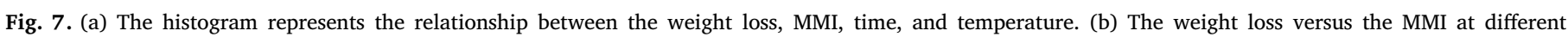
temperatures. Different colors in the histogram represent different temperatures, and the colors are the same as in the legend. 
temperatures under isothermal conditions are obtained by simulation, and the MMI of OM is calculated. The rate of change of the MMI increases with increasing temperature (Fig. 9a). As shown in Fig. 9b, the temperature has a more significant effect on the reaction rate at the beginning of the reaction. At high temperatures, the MMI increases rapidly at the beginning of the reaction. The rate of change of the MMI $\left(\Delta m / \Delta t^{*}\right)$ decreases and tends to be similar at different temperatures.

The initial stage of the kerogen has to be defined to analyze the evolution of kerogen. We assume that complete carbonization is the final state of kerogen; the conversion of the MMI is defined as:

$x=\frac{m-m_{0}}{1-m_{0}}$

where $m_{0}$ is the initial MMI of the kerogen sample, and 1 represents the mature state of kerogen. $m$ is calculated by Eq. (2). When $m=1$, the kerogen is fully mature, and the kerogen conversion is 1 . When $m=m_{0}$, no conversion occurs.

The conversion $x$ is used to characterize the degree of kerogen conversion. In previous studies, the conversion was defined as $x_{\text {pre }}=\left(W_{0}-W_{t}\right) /\left(W_{0}-W_{\infty}\right)$, where $W_{0}, W_{\infty}$, and $W_{t}$ are initial mass, final mass, and mass of sample at time $t$, respectively $[68,69]$. The conversion $x_{\text {pre }}$ is not directly related to changes in the kerogen structure, and can, therefore, not be related to the kinetic parameters. The evolution analysis is performed using the kinetic equation of solid-state decomposition [3770]:

$\frac{\mathrm{d} x}{\mathrm{~d} t}=k f(x)$

where $k$ is the rate constant $\left(\mathrm{s}^{-1}\right)$ and $f(x)$ is the function of the reaction model [37]. Here, the Arrhenius equation is used to establish the models of hydrocarbon generation [43]. In this study, we assume that the rate constant $k$ and temperature $T$ also satisfy the equation. The Arrhenius equation is $k=v \mathrm{e}^{-E / R T}$; Eq. (4) can be written as:

$\frac{\mathrm{d} x}{\mathrm{~d} t}=\nu \mathrm{e}^{-E / R T} f(x)$

where $t, \nu, E, R$, and $T$ are the time (s), the pre-exponential factor $\left(\mathrm{s}^{-1}\right)$, the apparent activation energy $(\mathrm{J} / \mathrm{mol})$, the gas constant $(\mathrm{J} / \mathrm{mol} / \mathrm{K})$, and the temperature $(\mathrm{K})$, respectively.

There are several forms of the reaction model that are based on the mechanism of the chemical reaction order, the random nucleation and growth (the Avrami-Erofeev equation), the phase boundary controlled reaction (geometrical model), and the diffusion mechanism. The equations of several models are listed to compare and select the models [43,69-74]: $f(x)=\left\{\begin{array}{cc}n x^{\frac{n-1}{n}} & \text { Power law } \\ n(1-x)[-\ln (1-x)]^{\frac{n-1}{n}} & \text { Avrami - Erofeev } \\ (1-x)^{n} & n^{\text {th }} \text { - order } \\ \frac{1}{2 x} & \text { 1D diffusion } \\ \frac{2}{3}(1-x)^{2 / 3}\left[1-(1-x)^{1 / 3}\right]^{-1} & \text { 3D diffusion } \\ n(1-x)^{\frac{n-1}{n}} & \text { Geometrical model }\end{array}\right.$

For isothermal reactions, the integration of Eq. (5) results in:

$g(x)=\nu \mathrm{e}^{-E / R T} t$

where $g(x)=\int f^{-1}(x) \mathrm{d} x$. Substituting Eq. (6) into Eq. (7), conversion $x$ can be calculated by:

$x=\left\{\begin{array}{cc}(k t)^{n} & \text { Power law } \\ 1-\mathrm{e}^{-(k t)^{n}} & \text { Avrami - Erofeev } \\ 1-\mathrm{e}^{-k t} & 1^{\text {st }}-\text { order } \\ 1-[1-(1-n) k t]^{1 /(1-n)} & n^{\text {th }}-\text { order }(\mathrm{n} \neq 1) \\ \sqrt{k t} & \text { 1D diffusion } \\ 1-\left[1-(k t)^{1 / 2}\right]^{3} & \text { 3D diffusion } \\ 1-(1-k t)^{n} & \text { Geometrical model }\end{array}\right.$

We established the relationship between $\ln (1-x)$ and $t$ to select the kerogen pyrolysis model under isothermal conditions. The curve approaches a straight line at low temperatures. A concave downward curve is obtained at high temperatures. In this case, we choose a distributed reaction model or a model in which the activation energy varies with the conversion. The Avrami-Erofeev equation is not applicable here because it is a sigmoidal reaction model. The fitting curves obtained from the basic model are shown in Fig. C1. The conversion is calculated based on the OM structure, and directly affects the activation energy. Thus, we develop a model in which the activation energy varies with the conversion. The model is a the first-order reaction kinetic equation at different stages of pyrolysis. The evolution of kerogen is described well by the first-order reaction model at low temperatures but not at high temperatures (Fig. 10). The nature of the reactant and the type of broken chemical bonds are changing during the evolution of kerogen. The maturity of $\mathrm{OM}$ is accelerated rapidly at high temperatures; therefore, the rate of change of the activation energy increases as the kerogen conversion rate increases. The MMI is inversely related to the $\mathrm{H} / \mathrm{C}$ and $\mathrm{O} / \mathrm{C}$ atomic ratios of OM. The increase in the MMI is accompanied by increases in the proportion of $\mathrm{C}-\mathrm{C}$ double bonds and aromaticity degrees and a decline in the heteroatoms in the $\mathrm{OM}$ $[55,58]$. The bond energy of C-heteroatoms $(\mathrm{O}, \mathrm{N}$ and $\mathrm{S})$ is lower than that of $\mathrm{C}-\mathrm{C}$, and the bond energies of the $\mathrm{C}-\mathrm{C}$ double bond and the $\mathrm{C}-\mathrm{C}$ (a)

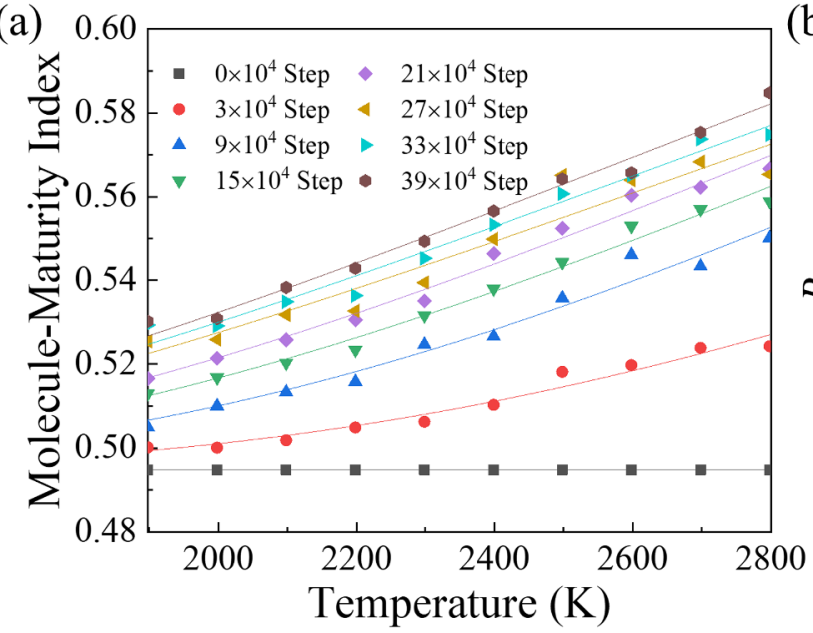

(b)

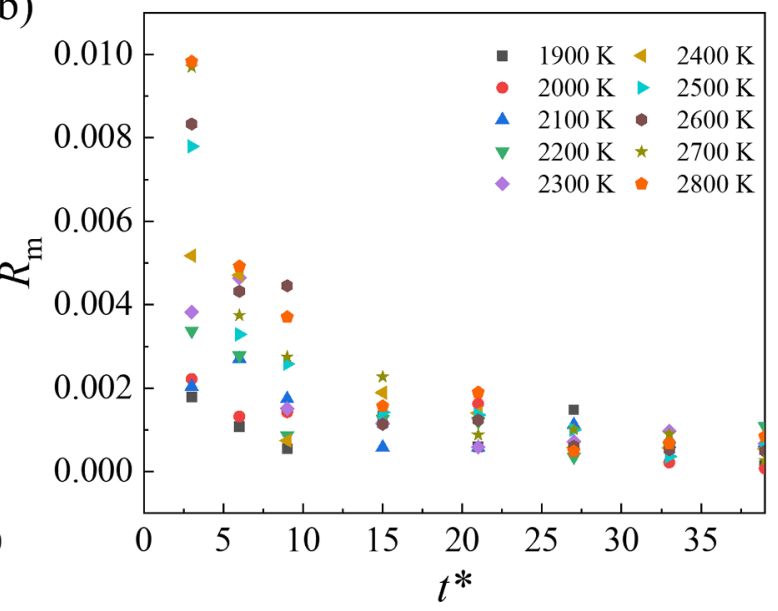

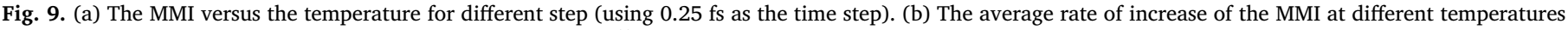
with an increment of $100 \mathrm{~K}\left(R_{m}=\Delta m / \Delta t *\right.$, where $\left.t *=4 t / 10^{-11} \mathrm{~S}\right)$. 

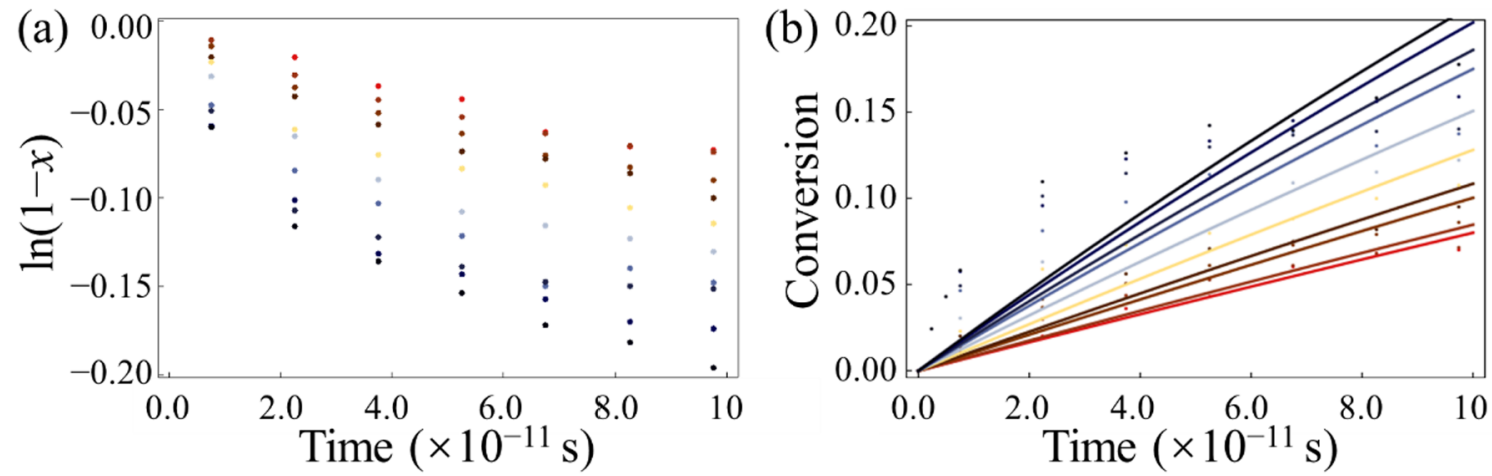

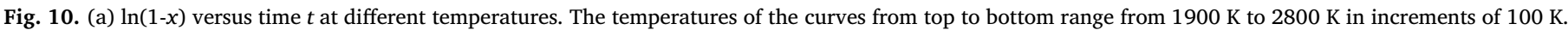

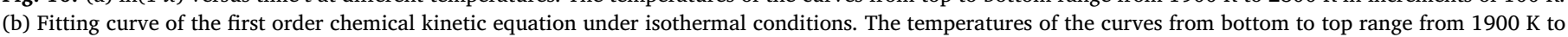
$2800 \mathrm{~K}$.

bond in benzene are higher than that of the $\mathrm{C}-\mathrm{C}$ single bond. The average bond energy in the molecule and the activation energy of the kinetic model increase with increasing MMI. Therefore, it can be considered that the activation energy is a function of $m$, and the conversion rate of $\mathrm{OM}$ declines with increasing $\mathrm{MMI}$ at the same temperature.

\subsubsection{The time-temperature-MMI relationship}

The first-order reaction kinetic model is selected to study the function of $E(m)$ :

$\frac{\mathrm{d} x}{\mathrm{~d} t}=\nu \mathrm{e}^{-E / R T}(1-x)$

where $E$ is an MMI-dependent variable. By substituting Eq. (3) into Eq. (9), we obtain:

$\frac{\mathrm{d}(m)}{\mathrm{d} t}=\nu(m) \mathrm{e}^{-E(m) / R T}(1-m)$

By taking logarithm on both sides of Eq. (10), the relationship of $m$ $T$ is expressed as follows:

$\ln \frac{\mathrm{d} m}{(1-m) \mathrm{d} t}=-\frac{E(m)}{R T}+\ln \nu(m)$

The least-squares method is used to obtain the $m$ - $t$ curves of the simulation data, as shown in Fig. 11; 16 sample points with $m$ ranging from 0.516 to 0.560 are used. The time $t$ corresponding to different temperatures is calculated under isothermal conditions for the same MMI. Subsequently, the derivative of the $m$ - $t$ curves for the corresponding data points is calculated. The item on the left side of Eq. (11) is obtained: $\left(L=\ln \frac{\mathrm{d} m}{(1-m) \mathrm{d} t}\right)$. When the MMI is higher than 0.536, there are fewer sampling points of $L$ because the MMI of partial simulations cannot be obtained. As shown in Fig. D1, the relationship between $L$ and $1 / T$ for the same MMI is approximately linear, which indicates that the first-order kinetic model is appropriate. For simplification, we assume that the pre-exponential factor is constant, and the linear relationship of $L-1 / T$ is obtained. The slopes are $-E / R$, and the intercept is $\ln v=29.63 \mathrm{~s}^{-1}$. The activation energies at different MMI values are obtained. As shown in Fig. 11, the activation energies $E$ increase with increasing $m$, and the relationship is approximately linear $(E=b+a m)$. The slope and intercept of the kerogen in this study are $a=855.11 \mathrm{KJ}$ and $b=-285.40 \mathrm{KJ}$. The activation energy of the sample ranges from $150 \mathrm{KJ}$ to $350 \mathrm{KJ}$. According to the previous chemical kinetic model based on the hydrocarbon generation rate, the activation energy of kerogen is around $200 \mathrm{KJ}$, but the range of the activation energy of type III kerogen is large (170-400 KJ) [75]. By substituting $E(m)$ into Eq. (11), the kinetic model of the maturity evolution (MEKM) is obtained:

$\frac{\mathrm{d} m}{\mathrm{~d} t}=v \mathrm{e}^{-(a m+b) / R T}(1-m)$
By integrating Eq. (12), the relationship among the time, temperature, and the MMI can be expressed as:

$t=\frac{\mathrm{e}^{b / R T}}{\nu} \int \frac{\mathrm{e}^{a m / R T}}{(1-m)} \mathrm{d} m$

Although the integral in Eq. (13) cannot be expressed as elementary functions, the value of the definite integral can be easily calculated by mathematical software such as Mathematica. In a previous study, the global first-order kinetic model did not adequately describe the evolution of kerogen due to the complex and non-uniform kerogen structure [76]. Common models that use $x_{\text {pre }}$ as the conversion include the Friedman, Kissinger-Akahira-Sunose (KAS) and Flynn-Wall-Ozawa (FWO) models. The activation energy curves and the forms of these models of activation energy are complex. For example, the kinetic parameters of the Friedman, KAS and FWO models are calculated at isoconversional points ranging from 0.1 to 0.9 (with an increment of 0.05 or 0.1 ). In addition, there are 11 parallel first-order reactions with different activation energies in a previous model [77]. These resulted in complex equations which are inconvenient for engineering use. However, our proposed kinetic model provides a straightforward approach to calculate the time required for the kerogen to mature to a certain value at different temperature. For this sample, the initial MMI of the kerogen sample is $m=0.495$. When VR greater than $2.0 \%$ Ro, the shale gas reservoirs have significant mining value. As shown in Fig. 3, the MMI is about 0.65 at $\%$ Ro $=2.0$ for type III kerogen. Table 2 shows the time required for the $\mathrm{OM}$ to reach a certain maturity (artificial

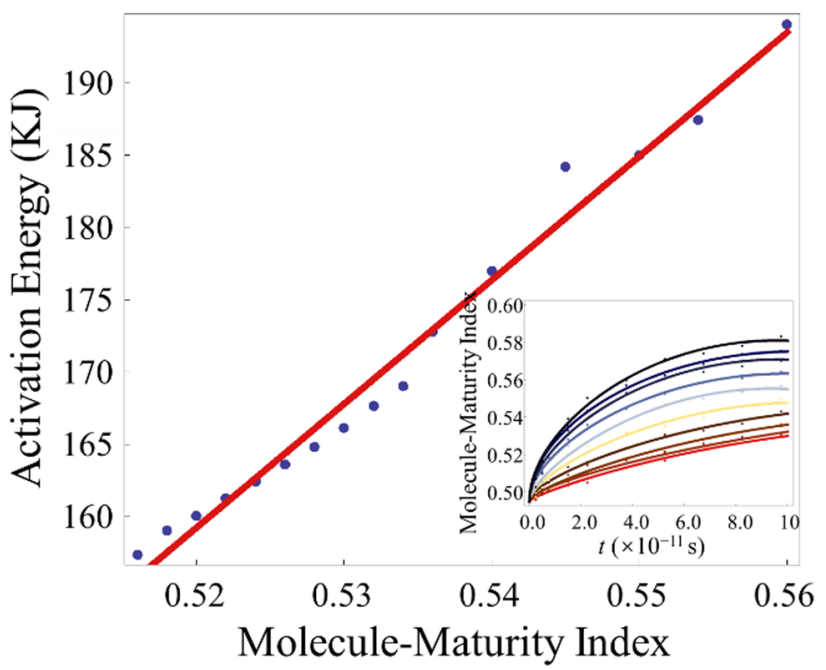

Fig. 11. The MMI versus the activation energy. The inset shows the $m-t$ fitted curves at different temperatures. 
Table 2

Time (s) to reach maturity at different temperature.

\begin{tabular}{|c|c|c|c|c|c|c|c|c|}
\hline$T\left({ }^{\circ} \mathrm{C}\right)$ & 100 & 200 & 300 & 400 & 500 & 600 & 700 & 800 \\
\hline$m=0.625$ & $7.67 \times 10^{19}$ & $4.50 \times 10^{12}$ & $9.05 \times 10^{7}$ & $4.62 \times 10^{4}$ & 170.05 & 2.30 & 0.076 & $4.75 \times 10^{-3}$ \\
\hline$m=0.650$ & $7.92 \times 10^{22}$ & $1.09 \times 10^{15}$ & $8.53 \times 10^{9}$ & $2.24 \times 10^{6}$ & $5.04 \times 10^{3}$ & 46.41 & 1.13 & 0.056 \\
\hline$m=0.675$ & $8.23 \times 10^{25}$ & $2.66 \times 10^{17}$ & $8.08 \times 10^{11}$ & $1.09 \times 10^{8}$ & $1.50 \times 10^{5}$ & 945.27 & 17.04 & 0.65 \\
\hline$m=0.700$ & $8.60 \times 10^{28}$ & $6.52 \times 10^{19}$ & $7.71 \times 10^{13}$ & $5.35 \times 10^{9}$ & $4.50 \times 10^{6}$ & $1.94 \times 10^{4}$ & 257.95 & 7.75 \\
\hline$m=0.725$ & $9.04 \times 10^{31}$ & $1.61 \times 10^{22}$ & $7.39 \times 10^{15}$ & $2.64 \times 10^{11}$ & $1.36 \times 10^{8}$ & $3.99 \times 10^{5}$ & $3.93 \times 10^{3}$ & 92.35 \\
\hline$m=0.750$ & $9.59 \times 10^{34}$ & $4.01 \times 10^{24}$ & $7.15 \times 10^{17}$ & $1.31 \times 10^{13}$ & $4.12 \times 10^{9}$ & $8.29 \times 10^{6}$ & $6.04 \times 10^{4}$ & $1.11 \times 10^{3}$ \\
\hline
\end{tabular}

maturity) under different isothermal conditions. Since the activation energy of OM increases with the increase in the MMI, the OM evolution becomes more difficult, and the hydrocarbon generation is slower at high MMI values. According to the experimental results in Ref. [78], the maturity of kerogen from 0.745 to $2.068 \%$ Ro requires $2.51 \times 10^{6} \mathrm{~s}$ under confined laboratory conditions at a temperature of $400{ }^{\circ} \mathrm{C}$. The corresponding MMI range is about 0.52-0.65. Equation (13) is used to calculate the required time in this range, which is $2.24 \times 10^{6} \mathrm{~s}$ at 400 ${ }^{\circ} \mathrm{C}$. This value is very close to the time obtained by the experiments, indicating that the relationship among time, temperature and the MMI still holds at lower temperatures. The equation can be used to choose the temperature and time for kerogen to reach artificial maturity. The MEKM needs to be further investigated and revised for kerogen evolution with a larger range of maturity, and the influence of pressure, heating rate, and minerals have to be analyzed. However, this work provides ideas for examining the chemical kinetic equation of kerogen pyrolysis based on the structure of $\mathrm{OM}$ and for determining the relationship between the activation energy and the MMI.

\section{Conclusions}

In summary, we proposed the MMI based on the $\mathrm{H} / \mathrm{C}$ and $\mathrm{O} / \mathrm{C}$ atomic ratios for evaluating kerogen maturity. An increase in the MMI indicates a decrease in the $\mathrm{H} / \mathrm{C}$ and $\mathrm{O} / \mathrm{C}$ atomic ratios. Thermal evolution experiments indicated a positive correlation between the MMI and the VR, a commonly used maturity index, thereby verifying the reliability of the MMI. MD simulations of the type III molecular model of kerogen from the Ordos basin demonstrated that the weight loss had a positive linear relationship with the MMI, accurately reflecting the hydrocarbon generation.

We investigated the changes in the MMI over time at different temperatures under isothermal conditions. The maturity evolution accelerated with increasing temperature, and the maturity rate decreased with increasing MMI at the same temperature. Several models of kinetic solid-state decomposition were used to establish the equations describing the kerogen maturity evolution; the first-order chemical kinetic equation was selected to investigate the relationship between the activation energy and the MMI.

The activation energy is related to the molecular structure of kerogen. The proposed conversion is directly related to maturity index; therefore, the relationship between the maturity index and the activation energy can be established. Simulations and numerical calculations indicated that the activation energy increased linearly with the MMI. The MEKM based on the first-order kinetic model was established, and it was found that the activation energy changed with the maturity. We determined the time to reach maturity of kerogen at different temperatures, which provides a method to select optimum time and temperature required for kerogen maturity in mining projects. Our findings provide insights into the evolution of kerogen at the molecular level and guidance to determine the heating temperature and heating time for artificial maturity. However, our work is based on simulations and on type III kerogen. The parameters corresponding to type I and type II kerogen, as well as the relationship between kinetic parameters and different types of kerogen, require further study to obtain a universal equation. Furthermore, we will conduct pyrolysis experiments on large rock masses and modify the current kinetic equations using a macro perspective for better applicability to actual conditions. The results of this study provide information on kerogen ripening, thereby improving oil and gas yields and reducing the costs of gas/oil exploitation.

\section{CRediT authorship contribution statement}

Xiaohe Wang: Methodology, Software, Formal analysis, Data curation, Writing - original draft, Visualization, Investigation, Writing review \& editing. Ya-Pu Zhao: Methodology, Resources, Funding acquisition, Supervision, Project administration.

\section{Declaration of Competing Interest}

The authors declare that they have no known competing financial interests or personal relationships that could have appeared to influence the work reported in this paper.

\section{Acknowledgements}

This work was jointly supported by the National Natural Science Foundation of China (NSFC, Grant No. 11872363, 51861145314), the Chinese Academy of Sciences (CAS) Key Research Program of Frontier Sciences (Grant No. QYZDJ-SSW-JSC019), and the CAS Strategic Priority Research Program (Grant No. XDB22040401).

\section{Appendix A. Kerogen pyrolysis process}

As shown in Fig. A1, pyrolysis of the marked part indicates the removal of the side chain in the kerogen. The C-heteroatom bonds and the chemical bonds in the middle of the long chain are more easily broken. Dehydrogenation can also be observed. This indicates that, the aromatic and double/triple bond-containing units in the residue increase during kerogen pyrolysis. 
(a)

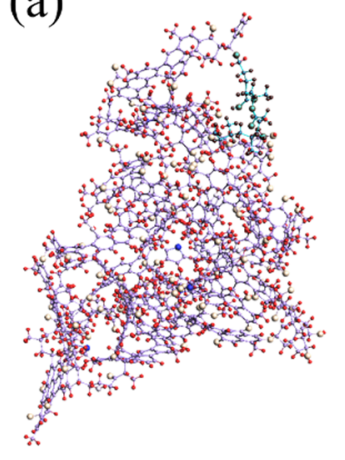

(b)

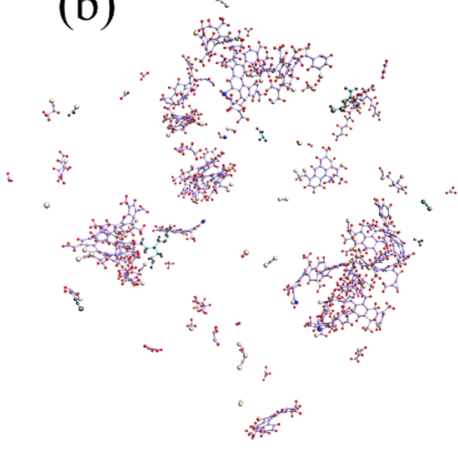

(c)

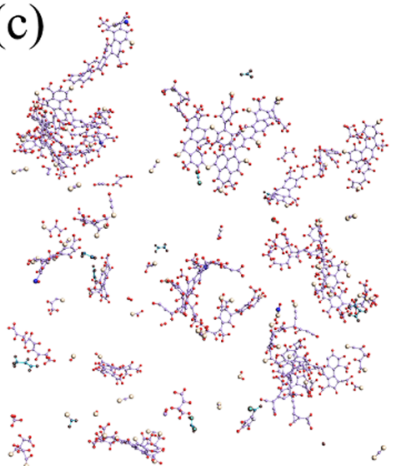

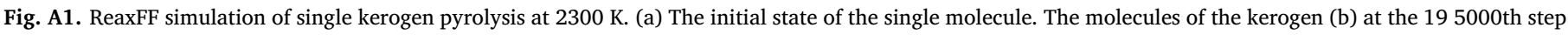
and (c) the 39 0000th step. The blue atoms are part of the long chain of kerogen.

\section{Appendix B. The relationship between the MMI and weight loss}

The atomic ratios of $\mathrm{H} / \mathrm{C}$ and $\mathrm{O} / \mathrm{C}$ of the kerogen residue are measured at different temperatures in the closed systems [66]. The MMIs are calculated. The relationship between the MMI and the weight loss is shown in Fig. B1.

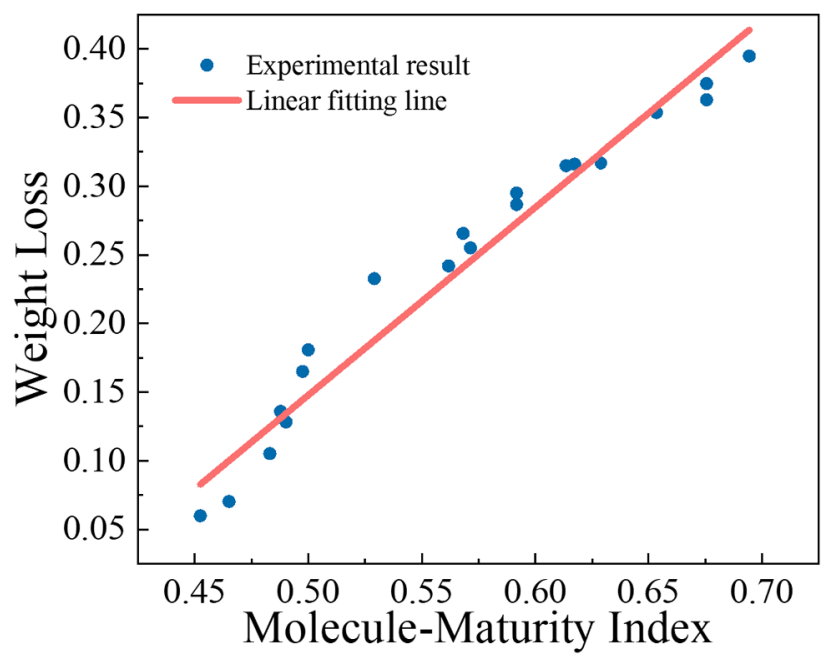

Fig. B1. The weight loss versus the MMI of Morwell coal; the data are from Ref. [66].

\section{Appendix C. Pyrolysis analysis using different basic kinetic models}

The relationship between $\times$ and $t$ at different temperatures is fitted by Eq. (8) to establish a suitable evolution model of the maturity. As shown in Fig. C1(a) and (b), the conversion curves based on the first-order reaction kinetic model and geometrical model $(n=3)$ are fitted very well at low temperatures, but the curves do not agree well with the simulation data at high temperatures. The Avrami-Erofeev equation $(n=2)$ cannot be used to fit the simulation results (Fig. C1(c)) due to the random nucleation and growth behavior. The reaction randomly initiates at multiple sites, and subsequently, each location expands in space. The reaction rate is directly proportional to the area of the reaction interface, but as the reaction occurs, the reaction interface begins to overlap. Therefore, the reaction rate increases first and then decreases, exhibiting a sigmoidal response and we cannot fit the curve. The reaction rate is proportional to the reaction interface area. The reaction interface area increases in the initial stage of the reaction, and then decreases as the reaction regions begin to overlap. The overall evolutionary trends of the $m$ - $t$ curves based on the diffusion and power law $(n=1 / 2)$ models are consistent with the simulation results; however, the errors in the initial stage of the evolution are substantial (Fig. C1(d-f)). The results show that none of the above equations satisfactorily meet our needs. The reason may be that kerogen contains a variety of functional groups. During the pyrolysis process, the types of chemical bonds change, and the broken bonds constantly change, resulting in changes in the reaction. Therefore, the activation energy changes during the pyrolysis process. The evolution of kerogen has been investigated using the firstorder kinetic equation, where the activation energy changes with the conversion, and the activation energy is calculated at the isoconversional points of the curve [77]. 
(a) 1-order: $f(x)=1-x$

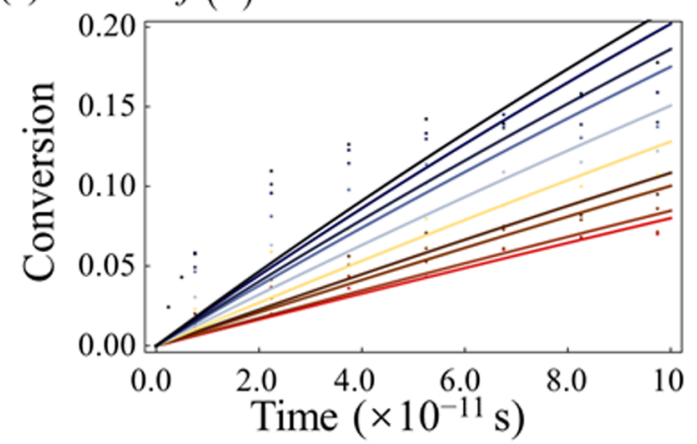

(c) Avrami-Erofeev: $f(x)=n(1-x)[-\ln (1-x)]^{\frac{n-1}{n}}$

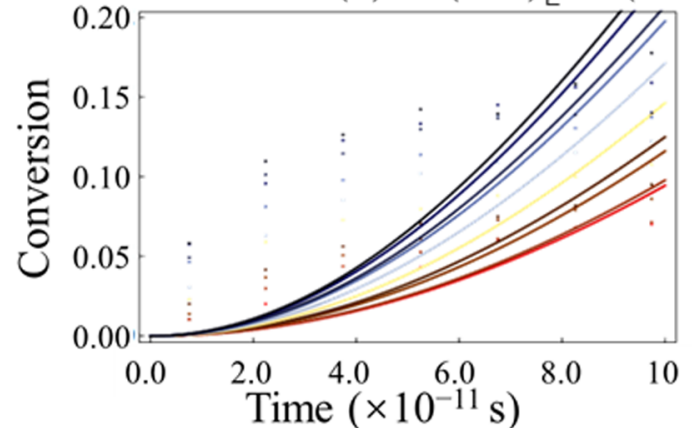

(e) 1D diffusion: $f(x)=\frac{1}{2 x}$

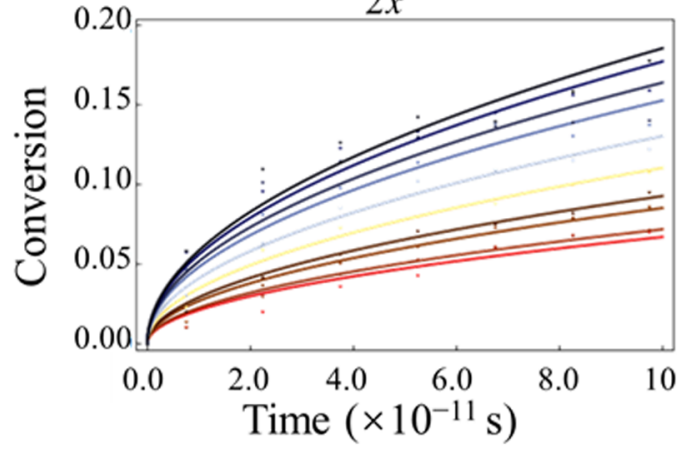

(b) Geometrical model: $f(x)=n(1-x)^{\frac{n-1}{n}}$

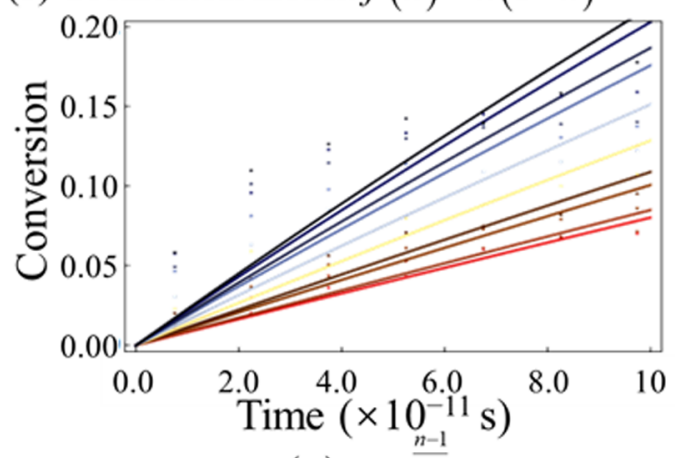

(d) Power law: $f(x)=n x^{n}$

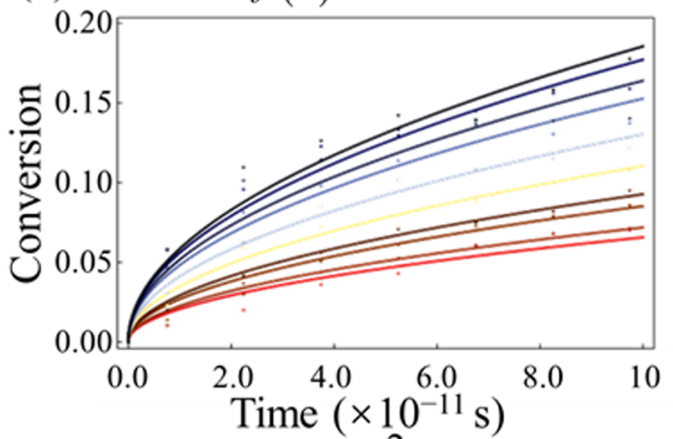

(f) 3D diffusion: $f(x)=\frac{2}{3}(1-x)^{2 / 3}\left[1-(1-x)^{1 / 3}\right]^{-1}$

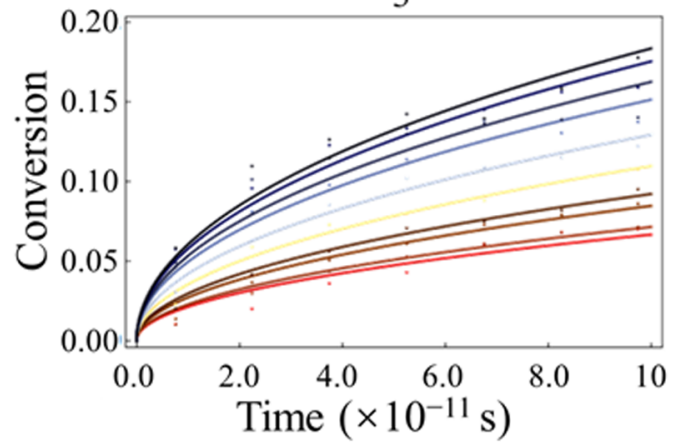

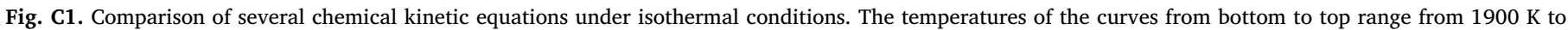
$2800 \mathrm{~K}$ in increments of $100 \mathrm{~K}$.

\section{Appendix D. Model reliability analysis}

As shown in Eq. (11), $L$ and 1/T need to satisfy a linear relationship if the first-order kinetic equation is used to describe the maturity evolution of kerogen. The values of $L$ of several indices are calculated at different temperatures, since we believe that the kinetic parameters change with the kerogen structure. Fig. D1 shows the change in $L$ with $1 / T$. The relationship is linear, indicating that the proposed kinetic equation is reasonable. The pre-exponential factor is fixed to simplify the kinetic equation. The relationship between the pre-exponential factor and activation energy is positive [52]. The change in the activation energy during the evolution is not monotonous and irregular both the pre-exponential factor and activation energy are used as fitting parameters. Since $k=\nu \mathrm{e}^{-E / R T}$, a fixed pre-exponential factor is chosen to determine the changes in the activation energy with changes in the kerogen structure, although this may reduce the accuracy. The median value of the pre-exponential factor obtained by fitting is selected, and this value is on the order of $10^{13}$ which is consistent with a previous study [79]. 

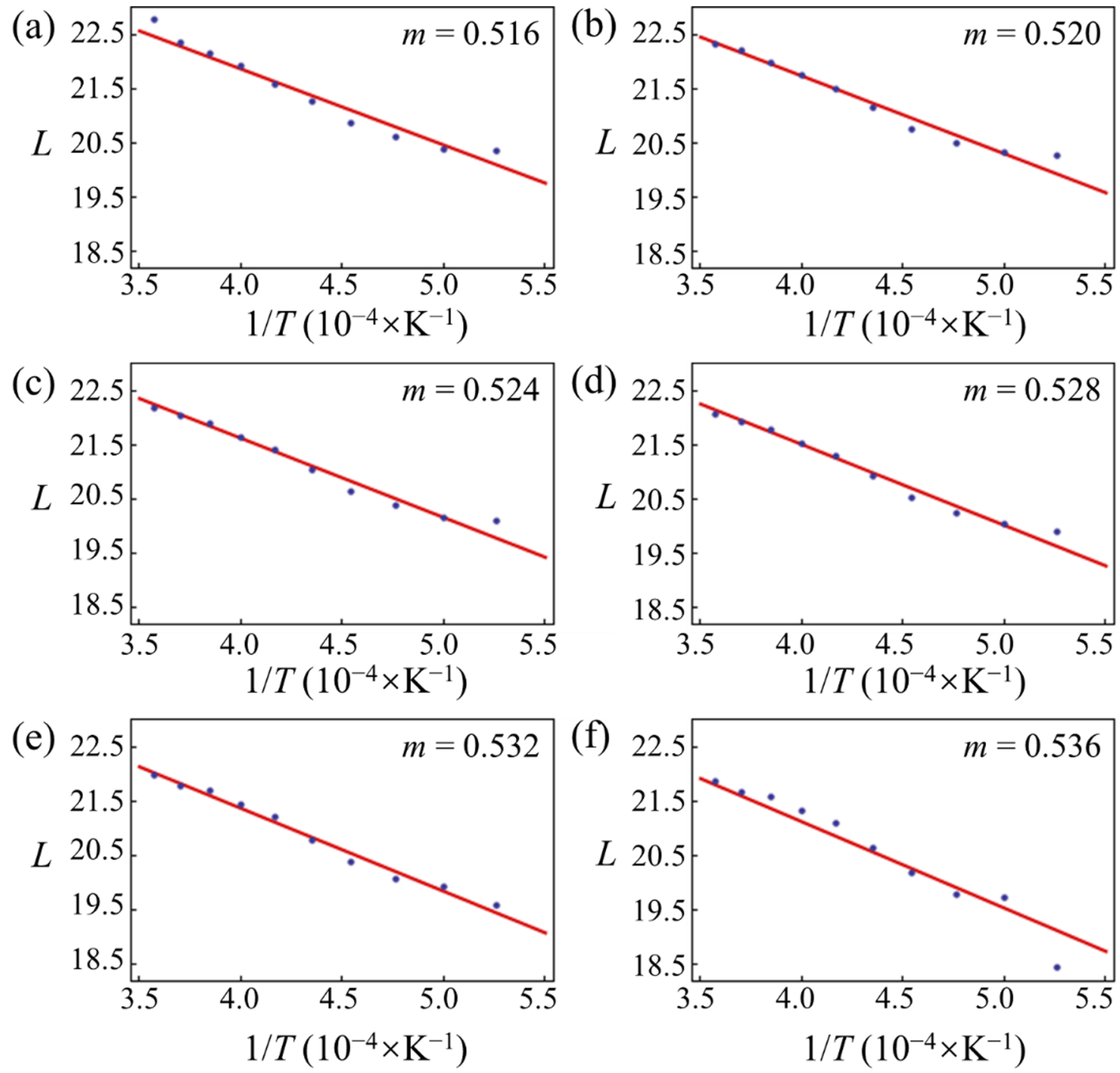

Fig. D1. Linear relationships between $L$ and $1 / T$.

\section{References}

[1] Chen B, Han X, Li Q, Jiang X. Study of the thermal conversions of organic carbon of Huadian oil shale during pyrolysis. Energ Convers Manage 2016;127:284-92.

[2] Vandenbroucke M, Largeau C. Kerogen origin, evolution and structure. Org Geochem 2007;38:719-833.

[3] Bousige C, Ghimbeu CM, Vix-Guterl C, Pomerantz AE, Suleimenova A, Vaughan G, et al. Realistic molecular model of kerogen's nanostructure. Nat Mater 2016:15:576-82.

[4] Thomas JJ, Valenza II JJ, Craddock PR, Bake KD, Pomerantz AE. The neutron scattering length density of kerogen and coal as determined by $\mathrm{CH} 3 \mathrm{OH} / \mathrm{CD} 3 \mathrm{OH}$ exchange. Fuel 2014;117:801-8.

[5] Gu X, Cole DR, Rother G, Mildner DF, Brantley SL. Pores in Marcellus shale: A neutron scattering and FIB-SEM study. Energy Fuels 2015;29:1295-308.

[6] Yu H, Chen J, Zhu Y, Wang F, Wu H. Multiscale transport mechanism of shale gas in micro/nano-pores. Int J Heat Mass Transfer 2017;111:1172-80.

[7] Huang X, Zhao Y-P. Characterization of pore structure, gas adsorption, and spontaneous imbibition in shale gas reservoirs. J Pet Sci Eng 2017;159:197-204.

[8] Yu H, Fan J, Chen J, Zhu Y, Wu H. Pressure-dependent transport characteristic of methane gas in slit nanopores. Int J Heat Mass Transfer 2018;123:657-67.

[9] Berthonneau J, Obliger A, Valdenaire P-L, Grauby O, Ferry D, Chaudanson D, et al. Mesoscale structure, mechanics, and transport properties of source rocks' organic pore networks. Proc Natl Acad Sci 2018;115:12365-70.

[10] Khatibi S, Aghajanpour A, Ostadhassan M, Ghanbari E, Amirian E, Mohammed R. Evaluating the impact of mechanical properties of kerogen on hydraulic fracturing of organic rich formations. SPE Canada Unconvent Res Conf Soc Petrol Eng 2018.

[11] Han Y, Al-Muntasheri G, Katherine LH, Abousleiman YN. Tensile mechanical behavior of kerogen and its potential implication to fracture opening in kerogen-rich shales (KRS), 50th US rock mechanics/geomechanics symposium. Am Rock Mech
Assoc 2016.

[12] Emmanuel S, Eliyahu M, Day-Stirrat RJ, Hofmann R, Macaulay CI. Impact of thermal maturation on nano-scale elastic properties of organic matter in shales. Mar Pet Geol 2016;70:175-84.

[13] Alstadt KN, Katti KS, Katti DR. Nanoscale morphology of kerogen and in situ nanomechanical properties of green river oil shale. J Nanomechanics Micr 2016;6:04015003.

[14] Zhang Y, Ran Z, Jin B, Zhang Y, Zhou C, Sher F. Simulation of Particle Mixing and Separation in Multi-Component Fluidized Bed Using Eulerian-Eulerian Method. A Review, Int J Chem React Eng 2019;17..

[15] Adeniyi AG, Otoikhian KS, Ighalo JO, Steam reforming of biomass pyrolysis oil: a review, Int J Chem React Eng 2019;17.

[16] Hai IU, Sher F, Zarren G, Liu H. Experimental investigation of tar arresting techniques and their evaluation for product syngas cleaning from bubbling fluidized bed gasifier. J Clean Prod 2019;240:118239.

[17] Waples DW. Geochemistry in petroleum exploration. 1st ed. Boston: Springer Science \& Business Media; 1985.

[18] Tahoun SS, Deaf AS, Gentzis T, Carvajal-Ortiz H. Modified RGB-based kerogen maturation index (KMI): Correlation and calibration with classical thermal maturity indices. Int J Coal Geol 2018:190:70-83.

[19] Riediger C. Solid bitumen reflectance and Rock-Eval Tmax as maturation indices: an example from the "Nordegg Member" Western Canada Sedimentary Basin. Int J Coal Geol 1993;22:295-315.

[20] Hackley PC, Lewan M. Understanding and distinguishing reflectance measurements of solid bitumen and vitrinite using hydrous pyrolysis: implications to petroleum assessment. AAPG Bull 2018;102:1119-40.

[21] Obermajer M, Stasiuk L, Fowler M, Osadetz K. Application of acritarch fluorescence in thermal maturity studies. Int J Coal Geol 1999;39:185-204.

[22] Sweeney JJ, Burnham AK. Evaluation of a simple model of vitrinite reflectance based on chemical kinetics. AAPG Bull 1990;74:1559-70. 
[23] Hartkopf-Fröder C, Königshof P, Littke R, Schwarzbauer J. Optical thermal maturity parameters and organic geochemical alteration at low grade diagenesis to anchimetamorphism: a review. Int J Coal Geol 2015;150:74-119.

[24] Thompson-Rizer CL, Woods RA. Microspectrofluorescence measurements of coals and petroleum source rocks. Int J Coal Geol 1987;7:85-104.

[25] Hackley PC, Walters CC, Kelemen SR, Mastalerz M, Lowers HA. Organic petrology and micro-spectroscopy of Tasmanites microfossils: applications to kerogen transformations in the early oil window. Org Geochem 2017;114:23-44.

[26] Róg L. Vitrinite reflectance as a measure of the range of influence of the temperature of a georeactor on rock mass during underground coal gasification. Fuel 2018;224:94-100

[27] Zhang Y, Li Z. Raman spectroscopic study of chemical structure and thermal maturity of vitrinite from a suite of Australia coals. Fuel 2019;241:188-98.

[28] Tissot BP, Pelet R, Ungerer P. Thermal history of sedimentary basins, maturation indices, and kinetics of oil and gas generation. AAPG Bull 1987;71:1445-66.

[29] Hai IU, Sher F, Yaqoob A, Liu H. Assessment of biomass energy potential for SRC willow woodchips in a pilot scale bubbling fluidized bed gasifier. Fuel 2019;258:116143.

[30] Mählmann RF, Le Bayon R. Vitrinite and vitrinite like solid bitumen reflectance in thermal maturity studies: Correlations from diagenesis to incipient metamorphism in different geodynamic settings. Int J Coal Geol 2016;157:52-73.

[31] Dang S, Sondergeld C, Rai C, Study of kerogen maturity using fourier transform infrared spectroscopy (FTIR) and thermogravimetric analysis (TGA), SPE Annual Technical Conference and Exhibition, Society of Petroleum Engineers, 2015.

[32] Chen Z, Chai Z, Cao Y, Liu Q, Zhang S, Yuan G. Suppression of thermal maturity indicators in lacustrine source rocks: A case study of Dongying Depression, eastern China. Mar Pet Geol 2019;109:108-27.

[33] Henderson S, Ghassal B, Overmature and Vitrinite-Barren Source Rocks: A Novel Thermal Maturity Parameter, SPE Middle East Oil and Gas Show and Conference, Society of Petroleum Engineers, 2019.

[34] Copard Y, Disnar J-R, Becq-Giraudon J-F. Erroneous maturity assessment given by $T_{\max }$ and HI Rock-Eval parameters on highly mature weathered coals. Int J Coal Geol 2002;49:57-65.

[35] Monthioux M, Landais P, Monin J-C. Comparison between natural and artificial maturation series of humic coals from the Mahakam delta, Indonesia. Org Geochem 1985;8:275-92.

[36] Tissot B, Durand B, Espitalie J, Combaz A. Influence of nature and diagenesis of organic matter in formation of petroleum. AAPG Bull 1974;58:499-506.

[37] Burnham AK. Kinetic models of vitrinite, kerogen, and bitumen reflectance. Org Geochem 2019;131:50-9.

[38] Burnham AK, Sweeney JJ. A chemical kinetic model of vitrinite maturation and reflectance. Geochim Cosmochim Acta 1989;53:2649-57.

[39] Baskin DK. Atomic H/C ratio of kerogen as an estimate of thermal maturity and organic matter conversion. AAPG Bull 1997;81:1437-50.

[40] Craddock PR, Bake KD, Pomerantz AE. Chemical, molecular, and microstructural evolution of kerogen during thermal maturation: case study from the Woodford Shale of Oklahoma. Energy Fuels 2018;32:4859-72.

[41] Tissot BP, Welte DH, Petroleum formation and occurrence. 2nd ed. New York: Springer Science \& Business Media; 1984.

[42] Aboulkas A, El Harfi K, Study of the Kinetics and Mechanisms of Thermal Decomposition of Moroccan Tarfaya Oil Shale and Its Kerogen, Oil Shale 2008;25.

[43] Li S, Yue C. Study of different kinetic models for oil shale pyrolysis. Fuel Process Technol 2004;85:51-61.

[44] Kok MV, Şengüler İ. Geological and thermal characterization of Eskişehir region oil shales. J Therm Anal Calorim 2014;116:367-72.

[45] Wang Q, Ma Y, Li S, Hou J, Shi J. Exergetic life cycle assessment of Fushun-type shale oil production process. Energ Convers Manage 2018;164:508-17.

[46] Lin Y, Liao Y, Yu Z, Fang S, Lin Y, Fan Y, et al. Co-pyrolysis kinetics of sewage sludge and oil shale thermal decomposition using TGA-FTIR analysis. Energ Convers Manage 2016;118:345-52.

[47] Sonibare OO, Ehinola O, Egashira R. Thermal and geochemical characterization of Lokpanta oil shales. Nigeria, Energ Convers Manage 2005;46:2335-44.

[48] Sher F, Iqbal SZ, Liu H, Imran M, Snape CE. Thermal and kinetic analysis of diverse biomass fuels under different reaction environment: A way forward to renewable energy sources. Energ Convers Manage 2020;203:112266.

[49] Rajeshwar K. The kinetics of the thermal decomposition of green river oil shale kerogen by non-isothermal thermogravimetry. Thermochim Acta 1981;45:253-63.

[50] Han H, Zhong N, Huang C, Zhang W. Pyrolysis kinetics of oil shale from northeast China: Implications from thermogravimetric and Rock-Eval experiments. Fuel 2015;159:776-83.

[51] Ma Y, Li S. The mechanism and kinetics of oil shale pyrolysis in the presence of water. Carbon Resources Con 2018;1:160-4.

[52] Bai F, Guo W, Lü X, Liu Y, Guo M, Li Q, et al. Kinetic study on the pyrolysis behavior of Huadian oil shale via non-isothermal thermogravimetric data. Fuel 2015;146:111-8.

[53] Tegelaar EW, Noble RA. Kinetics of hydrocarbon generation as a function of the molecular structure of kerogen as revealed by pyrolysis-gas chromatography. Org Geochem 1994;22:543-74.

[54] Shawabkeh A, Abdel Halim K, Al-Ayed O, Isoconversional Methods for Kinetic Modeling of Kerogen Pyrolysis Using TG Data, Applied Mechanics and Materials, Trans Tech Publ, 2016, pp. 299-307.

[55] Wang X, Huang X, Lin K, Zhao Y-P. The constructions and pyrolysis of 3D kerogen macromolecular models: experiments and simulations. Glob Chall 2019;3:1900006.

[56] Zhao Y-P. Physical mechanics of surfaces and interfaces. 1st ed. Beijing: Science Press; 2012.

[57] Castro-Marcano F, Russo Jr MF, van Duin AC, Mathews JP. Pyrolysis of a large-scale molecular model for Illinois no. 6 coal using the ReaxFF reactive force field. J Anal Appl Pyrolysis 2014;109:79-89.

[58] Wei X, Zhong H, Yang Q, Yao E, Zhang Y, Zou H. Studying the mechanisms of natural rubber pyrolysis gas generation using RMD simulations and TG-FTIR experiments. Energ Convers Manage 2019;189:143-52.

[59] Liu X, Zhan JH, Lai D, Liu X, Zhang Z, Xu G. Initial pyrolysis mechanism of oil shale kerogen with reactive molecular dynamics simulation. Energy Fuels 2015;29:2987-97.

[60] Salmon E, van Duin AC, Lorant F, Marquaire P-M, Goddard III WA, Early maturation processes in coal. Part 2: Reactive dynamics simulations using the ReaxFF reactive force field on Morwell Brown coal structures, Org Geochem 2009;40:1195209.

[61] Wang QD, Wang JB, Li JQ, Tan NX, Li XY. Reactive molecular dynamics simulation and chemical kinetic modeling of pyrolysis and combustion of n-dodecane. Combust Flame 2011;158:217-26.

[62] Wang QD, Hua XX, Cheng XM, Li JQ, Li XY. Effects of fuel additives on the thermal cracking of n-decane from reactive molecular dynamics. J Phys Chem A 2012;116:3794-801.

[63] Duan D, Zhang D, Ma X, Yang Y, Ran Y, Mao J. Chemical and structural characterization of thermally simulated kerogen and its relationship with microporosity. Mar Pet Geol 2018;89:4-13.

[64] Du J, Geng A, Liao Z, Cheng B. Potential Raman parameters to assess the thermal evolution of kerogens from different pyrolysis experiments. J Anal Appl Pyrolysis 2014;107:242-9.

[65] Mao J, Fang X, Lan Y, Schimmelmann A, Mastalerz M, Xu L, et al. Chemical and nanometer-scale structure of kerogen and its change during thermal maturation investigated by advanced solid-state 13C NMR spectroscopy. Geochim Cosmochim Acta 2010;74:2110-27.

[66] Behar F, Vandenbroucke M, Teermann S, Hatcher P, Leblond C, Lerat O. Experimental simulation of gas generation from coals and a marine kerogen. Chem Geol 1995;126:247-60.

[67] Storm DA, DeCanio SJ, DeTar MM, Nero VP. Upper bound on number average molecular weight of asphaltenes. Fuel 1990;69:735-8.

[68] Foltin JP, Lisboa ACL, de Klerk A. Oil shale pyrolysis: Conversion dependence of kinetic parameters. Energy Fuels 2017;31:6766-76.

[69] Kuang W, Lu M, Yeboah I, Qian G, Duan X, Yang J, et al. A comprehensive kinetics study on non-isothermal pyrolysis of kerogen from Green River oil shale. Chem Eng J 2019;377:120275.

[70] Aboulkas A, El Bouadili A. Thermal degradation behaviors of polyethylene and polypropylene Part I: Pyrolysis kinetics and mechanisms. Energ Convers Manage 2010;51:1363-9.

[71] Šesták J, Berggren G. Study of the kinetics of the mechanism of solid-state reactions at increasing temperatures. Thermochim Acta 1971;3:1-12.

[72] Vyazovkin S, Burnham AK, Criado JM, Pérez-Maqueda LA, Popescu C, Sbirrazzuoli N. ICTAC Kinetics Committee recommendations for performing kinetic computations on thermal analysis data. Thermochim Acta 2011;520:1-19.

[73] Hu M, Chen Z, Wang S, Guo D, Ma C, Zhou Y, et al. Thermogravimetric kinetics of lignocellulosic biomass slow pyrolysis using distributed activation energy model Fraser-Suzuki deconvolution, and iso-conversional method. Energ Convers Manage 2016;118:1-11.

[74] Ko KH, Rawal A, Sahajwalla V. Analysis of thermal degradation kinetics and carbon structure changes of co-pyrolysis between macadamia nut shell and PET using thermogravimetric analysis and 13C solid state nuclear magnetic resonance. Energ Convers Manage 2014;86:154-64.

[75] Yang G, Wu Z, Xu W, Qian J. Study on kinetics of hydrocarbon-genereting pyrolysis of different kinds of kerogen (2) Journal of the University of Petroleum. China 1990;1990:11.

[76] Burnham AK, Braun RL, Coburn TT, Sandvik EI, Curry DJ, Schmidt BJ, et al. An appropriate kinetic model for well-preserved algal kerogens. Energy Fuels 1996;10:49-59.

[77] Li S, Yue C. Study of pyrolysis kinetics of oil shale. Fuel 2003;82:337-42.

[78] Le Bayon R, Brey GP, Ernst W, Mählmann RF. Experimental kinetic study of organic matter maturation: time and pressure effects on vitrinite reflectance at $400^{\circ} \mathrm{C}$. Org Geochem 2011;42:340-55.

[79] Burnham AK. Global chemical kinetics of fossil fuels, How to model maturation and pyrolysis. 1st ed. USA: Springer; 2017. 